\title{
Tecnología, iconografía y ritual funerario. Tres dimensiones de análisis de los textiles formativos del sitio Punta de la Peña 9 (Antofagasta de la Sierra, Argentina)
}

SARa M. L. López CAMPenY ${ }^{1}$

\section{RESUMEN}

Los textiles desempeñaron en el mundo andino una variada gama de funciones, integrándose a múltiples aspectos de la vida cotidiana y de la esfera de las prácticas rituales. En este trabajo abordo tres dimensiones de análisis textil, a partir del estudio de prendas recuperadas en un contexto funerario de un sitio agropastoril temprano $(400$ a 550 DC) de la Puna Meridional Argentina. La dimensión tecnológica, a partir de la cual identifico elementos de continuidad y variabilidad textil en el espacio andino meridional; la dimensión iconográfica, a través de la cual analizo pautas de simetría y decoración, contextualizo cronológica y culturalmente las prendas y planteo relaciones de interacción con el norte de Chile; y finalmente, la dimensión ritual, la cual posibilitó abordar la participación y el significado de ciertos atributos textiles en algunas prácticas del rito funerario.

Palabras claves: Textiles - Período Formativo - Puna Meridional Argentina.

\begin{abstract}
In Andean world, textiles performed a variety of roles, integrating multiple aspects of daily life and ritual practices. In this work, I deal with three dimensions of textile analysis, based on research of items recovered from a funerary context of a Formative site (400 a 550 AD) in the Meridional Puna of Argentina. The technological dimension allowed to identify elements of textile continuity and variability in the Andean Meridional territory; the iconographical dimension, through which I analyze patterns of symmetry and decoration, contextualize cloths culturally and chronologically and state relations of interaction with Northern Chile; and last, the ritual dimension that allowed to deal with the participation and meaning of certain textile attributes in some practices of the funerary ceremony.
\end{abstract}

Key words: Textiles - Formative Period - Meridional Puna of Argentina.

Becaria CIUNT. Instituto de Arqueología y Museo. Facultad de Ciencias Naturales. Universidad Nacional de Tucumán. San Martín 1545. C.P.: 4000. San Miguel de Tucumán. Email: saralopezc@arnet.com.ar

\section{Introducción}

Incluida dentro de lo que se conoce como el Sector Meridional de la Puna Argentina, la microrregión de Antofagasta de la Sierra se localiza en el ángulo noroeste de la provincia de Catamarca. Constituye una suerte de oasis en un ambiente desértico, ya que la presencia de cursos de agua permanentes o semipermanentes origina vegas y ambientes relativamente aptos para el cultivo y el desarrollo de poblaciones sedentarias. Desde una perspectiva regional, Olivera (1992: 54) ha observado una serie de diferencias de tipo ecológicas y topográficas que le permitieron dividir a esta región, en tres sectores de acuerdo con el tipo de recursos presentes: 1) Fondo de cuenca (3.400 a $3.550 \mathrm{~m} . \mathrm{snm}$ ), 2) Sectores Intermedios (3.550 a 3.800 m.snm) y 3) Quebradas de altura (3.800 a $4.600 \mathrm{~m} . \mathrm{snm})$.

El sitio Punta de la Peña 9 (en adelante PP9) se localiza en los sectores intermedios de la cuenca del río Las Pitas, siendo sus coordenadas geográficas: $26^{\circ} 01$ ' $616^{\prime \prime}$ Lat. Sur y $67^{\circ} 20^{\prime} 513$ " Long. Oeste, y su altitud de $3.620 \mathrm{~m}$.snm. Lo que se ha denominado sector III, corresponde a un conjunto de cinco estructuras arquitectónicas ubicadas próximas a un farallón de ignimbritas que constituye el límite este del sitio. Las estructuras arquitectónicas presentan forma predominantemente circular, con muros de piedra, sin argamasa, los que se han levantado utilizando la materia prima local, es decir, rocas de ignimbrita. Una de las estructuras habitacionales que conforman este sitio (Est. 2) se seleccionó como unidad de estudio para identificar el conjunto de actividades realizadas, efectuar un análisis de la organización espacial interna e investigar la variabilidad o continuidad en el uso dado al espacio, a lo largo de las sucesivas ocupaciones que se registraron. ${ }^{2}$ Fue

2 Las investigaciones se desarrollaron en el marco de los Proyectos PIP 4975 y CIUNT G105, financiados por el 
seleccionada por presentar notables diferencias con el resto de las estructuras vecinas en la morfología de la planta y en su forma general de construcción. Estas características se relacionan, fundamentalmente, con el aprovechamiento de dos grandes bloques de derrumbe a modo de muros y como sostén para la colocación de vigas para techar el espacio de ocupación, a los que se anexó un pircado lateral de piedra. Uno de estos bloques presenta en su cara superior un conjunto de grabados rupestres y delimita un pasillo de acceso al espacio antiguamente techado.

El análisis detallado de la estratigrafía y de la distribución espacial de los contextos, junto con la información aportada por los fechados obtenidos para algunos de los eventos de ocupación identificados, permitió constatar una recurrencia en el uso del espacio intrasitio a lo largo de un período cercano a los 1500 años, con dataciones comprendidas entre 2000 y 500 años AP. Asimismo, permitió verificar que cada una de estas reocupaciones implicaron un uso diferencial de los espacios, con cambios registrados en el conjunto de actividades llevadas a cabo, en la funcionalidad y, posiblemente, en la significación otorgada por los propios usuarios a cada uno de esos lugares de uso, a lo largo del lapso mencionado (López Campeny 2001a y 2001b).

\section{El contexto funerario de hallazgo ¿El viaje de la muerte o los muertos se van de viaje?}

Una de las ocupaciones identificadas en la Estructura 2 se vinculó con el hallazgo de un contexto funerario localizado al reparo del bloque con grabados. El primer indicador, a aproximadamente $15 \mathrm{~cm}$ de profundidad, consistió en un conjunto de rocas de ignimbrita unidas con una argamasa de color rosado que contiene minerales arcillosos. La roca con grabados también presentaba la superficie inferior manchada con la misma argamasa. Este alineamiento de piedras presenta una forma aparentemente rectangular, ya que no todos sus límites se presentan en forma continua ni pueden identificarse con claridad. En el sector

CONICET y la Secretaría de Ciencia y Técnica de la UNT (CIUNT). Ambos proyectos fueron dirigidos por el Lic. Carlos Aschero. Asimismo, esta investigación se llevó a cabo como parte de una beca de Pre-Grado otorgada por el CIUNT a la autora de este trabajo, bajo la dirección de la Lic. Jorgelina García Azcárate. oeste la estructura presenta una extensión de 80 $\mathrm{cm}$, el límite sur conserva una extensión de piedras de aproximadamente $90 \mathrm{~cm}$ y el borde este no presenta ninguna construcción de piedras, sino que la excavación cuidadosa nos permitió identificar el límite de la fosa funeraria cavada en la propia ignimbrita disgregada, por una extensión de aproximadamente $1 \mathrm{~m}$. El límite norte, en cambio, no está claramente definido, ya que no existe ninguna alineación de piedras, ni rastros de la excavación original de la fosa. Sólo documentamos la presencia de una roca de importantes dimensiones $(25 \times 50 \mathrm{~cm})$ ubicada a $1 \mathrm{~m}$ de distancia de la intersección entre los límites sur y este, pero no hay mayores indicios de la extensión original de la fosa en este extremo lateral (López Campeny 2001a). La distribución de otra serie de piedras en el interior de esta estructura principal mostraba una aparente subdivisión interna en tres sectores de forma circular. Sin embargo, se pudo constatar que se trataba de rocas sueltas entre el relleno de sedimento y los materiales del ajuar, y que no conformaban tal subdivisión. Las mismas presentaban manchas de argamasa en alguna de sus superficies lo que, sumado al hallazgo de argamasa suelta entre el sedimento, permiten plantear que se trata de rocas que inicialmente formaban parte de la estructura principal y que fueron desprendidas de la misma. Explicaré a continuación cómo interpreto esta evidencia en relación con otros elementos particulares del contexto.

Asociados a las prendas textiles que constituyen el objeto de análisis de este trabajo, se recuperaron dos escudillas de cerámica (una gris pulida y otra decorada con pintura tricolor), tres "paquetes" o envolturas de cuero rellenos con vegetales y asegurados con cordelería de fibra vegetal y animal, cuentas de collar (malaquita y valva), una valva completa de un caracol marino (Familia Fissurellidae), ${ }^{3}$ un recipiente confeccionado sobre una media calabaza (Lagenaria siceraria) ${ }^{4}$ que exhibe trazos efectuados con pintura roja, un posible palo cavador intencionalmente fracturado y un conjunto de vegetales compuesto por carozos

\footnotetext{
3 La identificación ha sido realizada por las zoólogas F. Drahg y Gabriela Cuezzo. Facultad de Ciencias Naturales e I.M.L.

4 La identificación de las especies vegetales leñosas y herbáceas ha sido realizada por la Dra. M. Fernanda Rodríguez. El conjunto de semillas y frutos ha sido identificado por el Profesor Emilio Ulibarri. Ambos, integrantes del Instituto de Botánica Darwinion, Buenos Aires.
} 
de chañar (Geoffroea decorticans), endocarpos de algarrobo (Prosopis sp.), granos de maíz (Zea mays) y cotiledones de poroto (Phaseolus sp.). Sin embargo, una característica particular de este contexto es que el conjunto de restos humanos recuperados en la tumba fue escaso, ya que estaba conformado sólo por tres uñas, dos mechones de cabello y un número muy reducido de restos óseos, estos últimos correspondientes a un individuo probablemente masculino de entre 5 y 7 años de edad. ${ }^{5}$ Este hecho, sumado a la falta de continuidad detectada en los límites de la estructura, el hallazgo de gran cantidad de argamasa suelta entre el sedimento de relleno, la identificación de piedras manchadas con argamasa, que habrían formado parte de la estructura funeraria entre el sedimento del relleno y la ausencia de elementos arquitectónicos que puedan vincularse con la tapa o cierre de la estructura funeraria, permitieron suponer que esta tumba no representó el lugar de descanso final de este individuo sino que, en algún momento posterior a su entierro original, se produjo la reapertura, el retiro del cuerpo, la reorganización de los materiales en un nuevo espacio y el posterior relleno de la tumba. Una de las consecuencias de este evento de reapertura, es la constatación de una reducción física del espacio funerario, hecho que ha sido inferido a partir de la comparación entre las dimensiones originales de la tumba y el espacio mucho menor, limitado además por un círculo de piedras, en el que fueron recuperados la casi totalidad de los materiales arqueológicos que formaban parte del ajuar (López Campeny 2001a y 2001b). Con respecto a la cronología asociada a estos eventos, se dispone de dos fechados radiocarbónicos que permiten estimar la fecha en que podría haber tenido lugar el entierro original, así como la fecha antes de la cual debió efectuarse la reapertura de la tumba (López Campeny 2001b). En relación con el primer evento, una muestra de semillas de chañar, recuperadas en asociación con los materiales que formaban parte del ajuar, proporcionó una datación de $1460 \pm 40$ años AP, corregida 1480 (UGA 9069). ${ }^{6}$ Sólo partiendo de la suposición de que estas semillas formaban parte de la ofrenda origi-

5 El conjunto incluye un peroné, un fragmento de cintura pélvica, un omóplato, una clavícula y fragmentos de costillas. La determinación ha sido realizada por la arqueóloga. M. Gloria Colaneri, Instituto de Arqueología y Museo, UNT.

6 Las muestras han sido procesadas en el laboratorio del Center for Applied Isotope Studies de la Universidad de Georgia. nal, podría asociarse su fecha de recolección con el evento de depositación de los restantes componentes de la tumba. Con respecto al evento de reapertura del depósito funerario, sólo puedo decir que debió ocurrir en algún momento anterior a la conformación del nivel superior, identificado como un basurero doméstico. Una muestra de carbón procedente de este último nivel ha sido datada en $530 \pm 50$ años AP, corregida 600 (UGA 9260), fecha antes de la cual, sobre la base de la relación estratigráfica entre los niveles, interpreto que debió tener lugar la reapertura de la tumba y el traslado del cuerpo.

Un importante conjunto de prendas textiles permaneció en este depósito, conservándose hasta nuestra intervención arqueológica, lo que hizo posible emprender su análisis detallado. El presente estudio es abordado desde lo que planteo como tres posibles dimensiones de aproximación a la materialidad textil, teniendo en cuenta las características particulares de la muestra y el contexto de recuperación de estas prendas: el aspecto tecnológico, el iconográfico y el ritual. Es importante aclarar que considero que existen además otros diferentes puntos de vista y perspectivas desde los que pueden ser analizados los textiles, sobre todo teniendo en cuenta la gran diversidad de funciones que desempeñaron y su activa participación en diferentes aspectos de la vida y de la muerte, en las comunidades andinas. Por lo tanto, la metodología que aquí planteo representa sólo una forma de acercarnos al conocimiento del complejo arte de la textilería.

\section{La dimensión tecnológica. Sobre la metodología de análisis empleada y los principales atributos técnicos relevados}

El abordaje de esta primera dimensión de las piezas textiles -en el caso de las telas- se concretó con el empleo de una ficha descriptiva ${ }^{7}$ en la que he registrado una serie de atributos técnicos y formales que consideré relevantes para tal fin (López Campeny 2001a). En esta sección defino el concepto de cada atributo y la metodología

\footnotetext{
7 La ficha de análisis que he utilizado se basó en un modelo proporcionado por la Dra. Diana Rolandi de Perrot (Directora del INAPL, Bs. As.) y la metodología empleada para relevar los atributos textiles ha seguido, en términos generales, los lineamientos de trabajo presentados por dicha investigadora (Rolandi de Perrot 1973).
} 
general utilizada para relevarlo en el material. Finalmente, presento los principales resultados obtenidos a partir del análisis técnico estructural.

Acerca de las formas, dimensiones, materias primas y estructura de los tejidos

En primer lugar, realicé la identificación de la pieza. Con este término hago referencia sencillamente a la determinación del tipo de prenda con que es posible vincular a cada pieza textil, fundamentalmente sobre la base de sus atributos de forma, dimensiones, bordes, costuras o algún otro elemento de su construcción que permitan relacionarla con una determinada estructura formal o funcional. La casi totalidad de la información que poseemos sobre la textilería arqueológica procede de contextos funerarios, debido a las menores probabilidades de conservación de este tipo de materiales en contextos domésticos. ${ }^{8} \mathrm{~A}$ pesar de eso, más de la mitad de la muestra textil procedente de la tumba de PP9 no ha podido ser identificada (Cuadro 1). Entre las formas reconocidas se destacan una pequeña bolsa o chuspa (Figura 1) y una túnica o unku (Figura 2). La palabra quechua chuspa designa, en términos generales, a una bolsa de pequeñas dimensiones, cuyo uso más generalizado actualmente es el de guardar hojas de coca. Se construyen a partir de una pieza rectangular tejida a telar, que luego se dobla sobre sí misma, cosiéndose los bordes laterales. Generalmente presentan una tira delgada cosida a cada extremo de la boca, lo que permite colgarla de los hombros o del cuello. Como analizaré con detalle más adelante, la chuspa recuperada en PP9 presenta una serie de atributos técnicos y decorativos que la convierten en una pieza notable en el

\footnotetext{
8 Del nivel superior al contexto funerario, fechado en $600 \pm$ 50 años AP, procede un conjunto de fragmentos textiles y cordelería que presenta una serie de diferencias técnicas con la muestra textil hallada en la tumba (López Campeny 2001a). Estos datos son coherentes con mi propuesta de una cronología más tardía para estos fragmentos $(1.300$ a $1.500 \mathrm{DC}$ ), con respecto a las piezas funerarias (400 a 550 DC). Pero, además de las diferencias tecnológicas, los dos conjuntos textiles presentan importantes diferencias de conservación. Las reducidas dimensiones de las piezas procedentes del nivel más tardío, las que además exhiben sus bordes quemados, así como el resto de materiales artefactuales y ecofactuales con ellas asociados, nos remiten a un contexto de descarte o área de basurero. La presentación de las características de este conjunto textil tardío será objeto de un trabajo futuro.
}

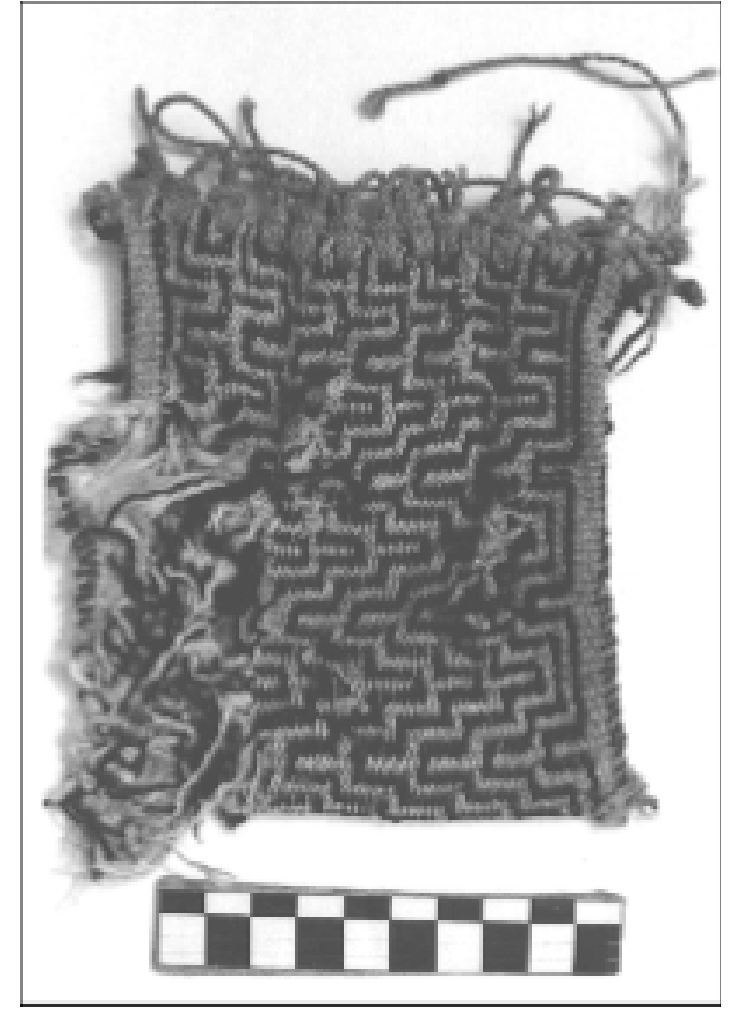

Figura 1. Pequeña bolsa decorada o chuspa.

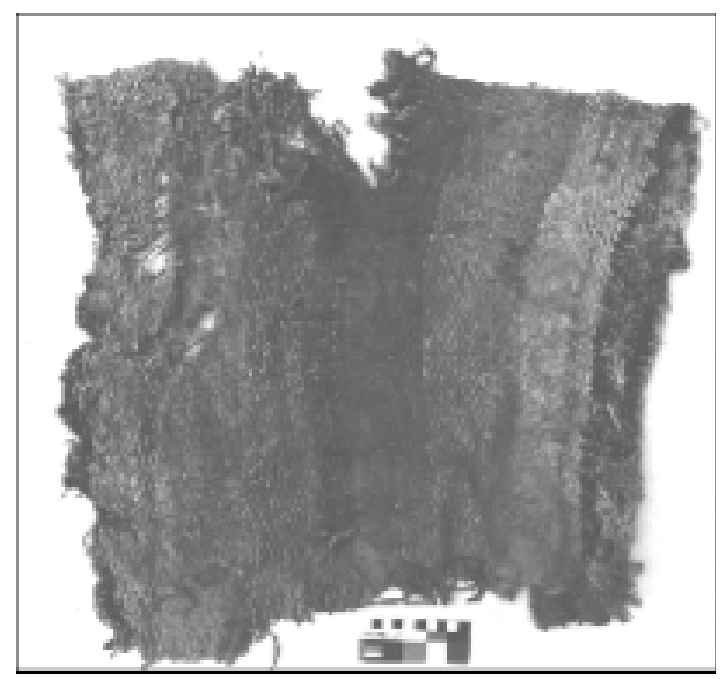

Figura 2. Foto de la túnica andina.

registro textil conocido para el N.O.A. Con respecto a la segunda pieza, el término quechua unkhu o unku (Lira 1944: 1043) se emplea para designar a una prenda andina formada por una pieza de forma generalmente rectangular que presenta un orificio central para el paso del cuello y 
dos orificios laterales para el paso de los brazos. Se obtiene tejiendo, en el telar, una pieza larga rectangular, dejando en el centro de la misma una abertura para el cuello, utilizando la técnica de tramas discontinuas o woven-slit openwork (Emery 1966: 65). La pieza, una vez tejida, se dobla por la mitad sobre sí misma, cosiéndose los bordes laterales y dejando únicamente las aberturas para permitir el paso de los brazos en la parte superior.

En forma aún tentativa, he vinculado a otra de las piezas con una manta (Figura 3). La identificación se ha efectuado, principalmente, en base a su forma rectangular y dimensiones. Además, como elementos adicionales, me he apoyado en otras características presentadas en forma recurrente por las numerosas mantas recuperadas en contextos funerarios formativos del norte de Chile (Azapa-70 y 71, Playa Miller-7, Tarapacá-40 y Topater-1), características que también fueron relevadas en la pieza de PP9. Hago referencia a su confección en faz de urdimbre con un aspecto "mullido" o grueso, el frecuente empleo de la técnica de tramas múltiples, la decoración por listas logradas, por la técnica de faz de urdimbre y la presencia de una costura decorativa en forma de cadeneta en el borde (Agüero 2000, Agüero y Cases 2000, Cases 2000, Horta 2000 Ms).

Otras dos piezas textiles lisas de grandes dimensiones han sido asociadas con posibles bolsas funerarias debido a que ambas consisten en telas de dimensiones semejantes que se unen por sus orillos laterales y sus bordes terminales a través de una serie de costuras. Esta determinación funcional se vincula no sólo con los atributos formales y técnicos mencionados, sino también con ciertas características del contexto. En primer lugar, por tratarse de piezas procedentes de una tumba y existir la práctica cultural, ampliamente documentada en el mundo andino, de emplear piezas textiles para envolver los cuerpos en fardos funerarios. A esto agregamos que una de las posibles bolsas presentaba, enrollados y anudados en la parte central, dos cordones compuestos confeccionados en cabello combinado con fibra de palmera (Acrocomia sp.), así como el hecho de que otros elementos gruesos de cordelería (en fibra animal y vegetal) se recuperaron asociados a la tumba. Estos elementos pueden haber servido como ataduras del fardo y el hecho de que se hayan recuperado sueltos e incluso fragmentados, sumado al hallazgo de las bolsas funerarias vacías, se relacionaría con las características particulares ya mencionadas en relación con el evento de reapertura de la tumba. Por último, es posible agregar el detalle de que el tamaño de estas prendas es coincidente con los datos bioantropológicos que vinculan a los restos óseos hallados en la tumba con un individuo infantil.

Finalmente, dos fragmentos decorados con diseños geométricos, pertenecientes originalmente a una misma pieza, podrían corresponder a una faja, un deformador cefálico, una vincha o algún tipo similar de adorno (Figura 4). Estas posibles vinculaciones se deducen de relacionar las di-

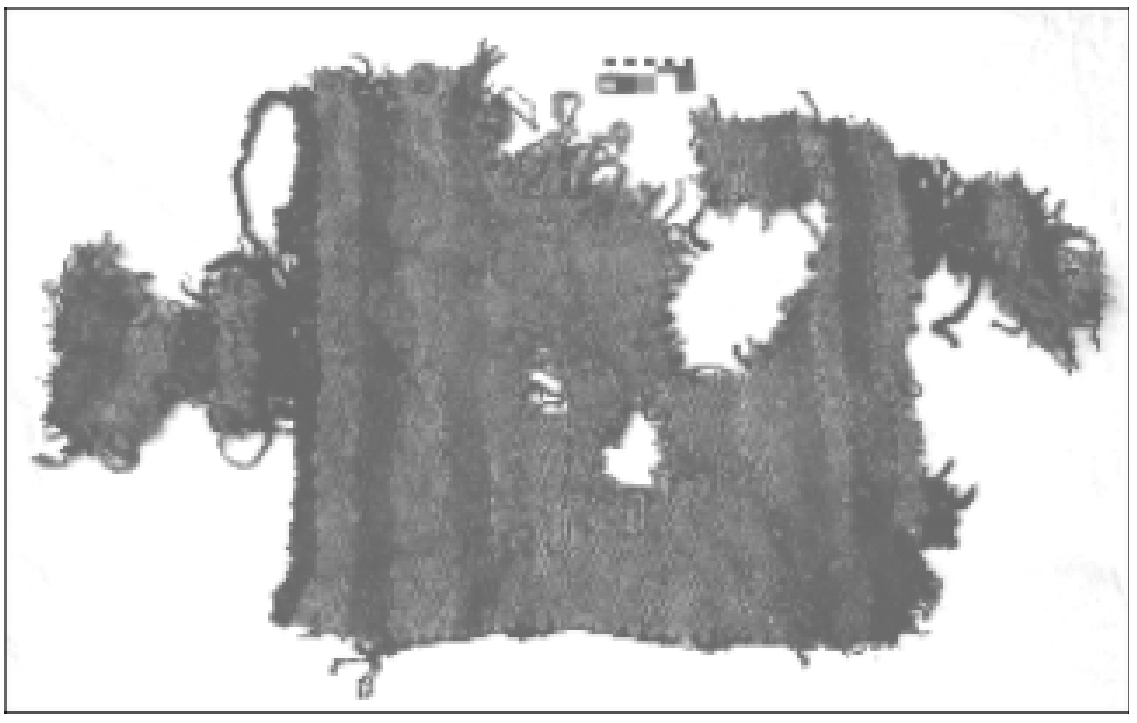

Figura 3. Posible manta decorada con listas. 
Figura 4. Fragmentos correspondientes a una posible faja, vincha o adorno similar.

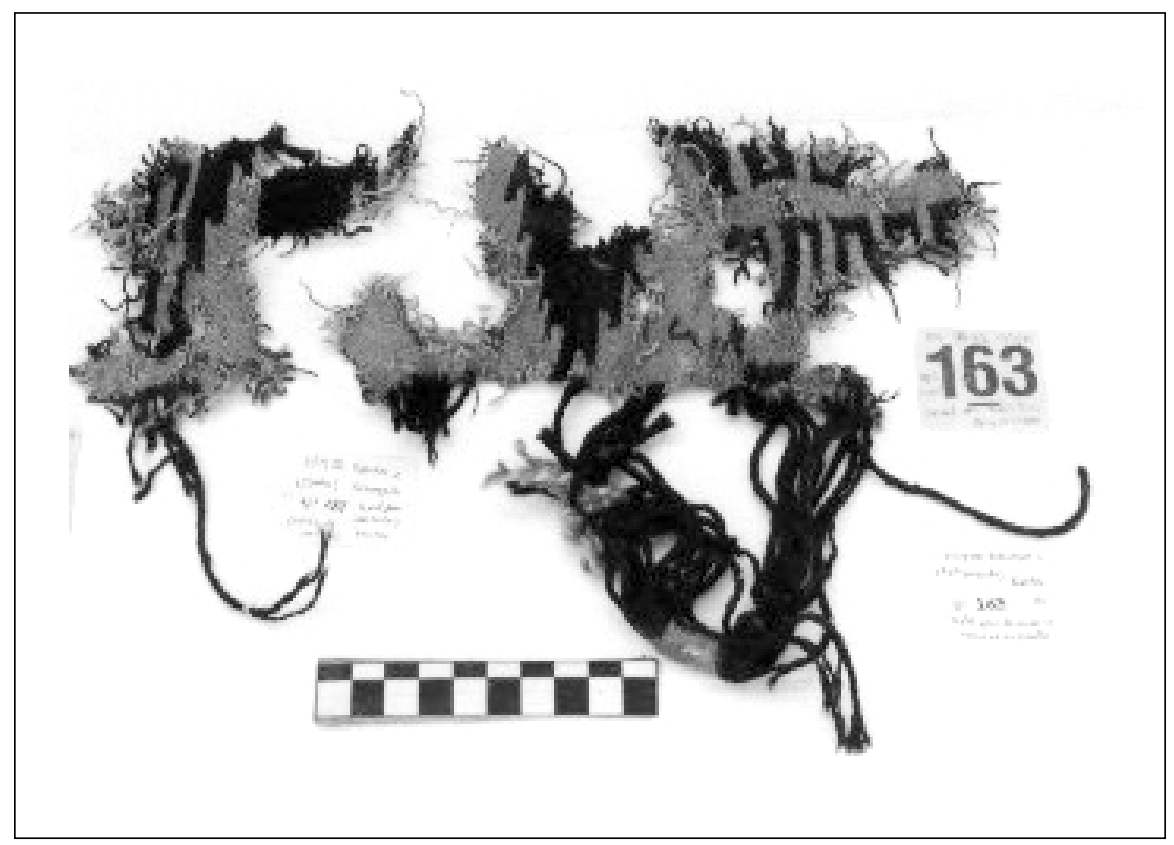

mensiones del ancho original de la pieza $(10 \mathrm{~cm})$, la presencia de elementos decorativos consistentes en flecos en el borde y la decoración lograda aplicando la técnica de tapicería, con las prendas que más frecuentemente han sido recuperadas como vestimenta funeraria en contextos agropastoriles andinos (Horta $2000 \mathrm{Ms}$ ). Las fajas y las cintas cefálicas constituyen elementos accesorios de la vestimenta prehispánica en el mundo andino y la mayor parte de estos artefactos proceden de contextos funerarios. Por lo tanto, los datos con los que se cuenta sobre su uso nos informan que, en el caso de las primeras, sujetan la túnica a la altura de la cintura, pero también se ha registrado su uso como ataduras para fijar los textiles que conforman fardos funerarios (Sinclaire 1995). De todas maneras, nuestro conocimiento sobre el material textil arqueológico del actual Noroeste argentino es aún demasiado fragmentario como para permitir llegar más lejos en la identificación.

El resto de las piezas, un total de doce fragmentos textiles que no he podido aún vincular con ninguna prenda, recibe en la ficha el nombre genérico de fragmento de tela.

Sólo el unku y la chuspa han conservado tanto los dos bordes de trama como ambos encabezamientos de urdimbre, por lo que constituyen ejem- plares en los que he podido determinar las dos principales dimensiones originales. Las dimensiones de algunas de las piezas más destacadas del conjunto son las siguientes. ${ }^{9}$ La bolsita tiene $25 \mathrm{~cm}$ (largo doble) por $10 \mathrm{~cm}$ (ancho). La túnica tiene $110 \mathrm{~cm}$ (largo doble) por $50 \mathrm{~cm}$ (ancho), la abertura de las mangas es de $20 \mathrm{~cm}$ (largo) y la del cuello de $26 \mathrm{~cm}$ (largo doble). La porción de la manta que se ha conservado es de $53 \mathrm{~cm}$ (largo) por 54 $\mathrm{cm}$ (ancho). Finalmente, uno de los fragmentos atribuibles a una faja y que conserva los dos orillos de trama mide $9 \mathrm{~cm}$ (largo) por $10 \mathrm{~cm}$ (ancho original), mientras que el segundo fragmento presenta $20 \mathrm{~cm}$ (largo) por $9.5 \mathrm{~cm}$ (ancho) como dimensiones principales.

El siguiente paso en el análisis correspondió a la identificación macroscópica de la materia prima con la que han sido confeccionados los tejidos. ${ }^{10}$

9 La descripción detallada de todo el conjunto textil de PP9 puede consultarse en López Campeny (2001a).

10 El análisis de las fibras de camélidos aún está pendiente. Sin embargo, la observación de los vellones y los hilados me ha permitido, en algunos casos, identificar la presencia de lana de vicuña por los colores claros y la extrema suavidad presentada al tacto por la fibra, mientras que, la presencia de vellones de fibra más larga, áspera y de colores marrones oscuros a casi negros sugiere la presencia de lana de llama o alpaca (López Campeny 2001a). Esto permite pensar que en los tejidos se podría estar combinando la 


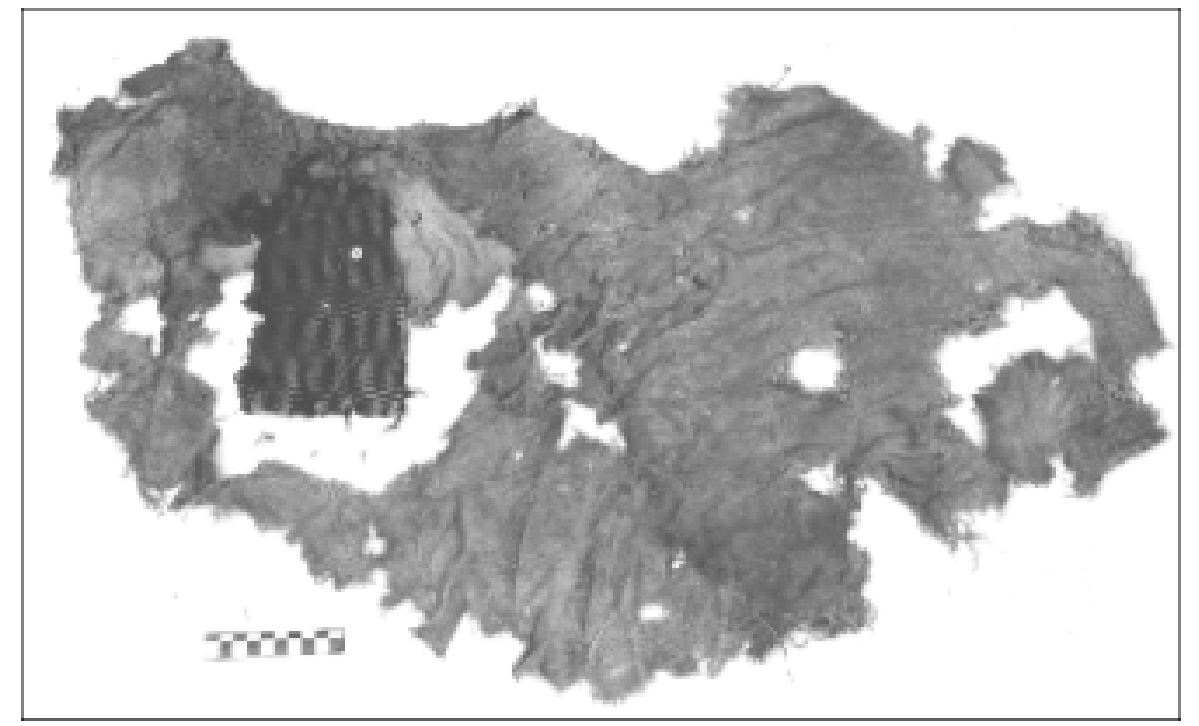

Figura 5. Pequeña tela decorada, unida por medio de una costura de cabello humano a una de las posibles bolsas funerarias.
Al respecto, podemos decir que todas las prendas tejidas en telar han sido elaboradas en fibra de camélido. No se han recuperado hilados de algodón, ni tejidos en fibra vegetal. Esta última materia prima ha sido utilizada para la confección de cordelería que acompaña a los tejidos como elemento accesorio. Finalmente, he registrado la utilización de cabello humano como elemento de costura, para unir una pieza decorada con motivos geométricos y de pequeñas dimensiones $(20 \mathrm{~cm} \mathrm{x} 14 \mathrm{~cm})$ a una de las prendas identificadas como bolsa funeraria (Figura 5). Si bien se trata de una pieza destacable por la técnica de construcción empleada para conseguir un diseño que es además sumamente notable, no hice referencia a ella anteriormente debido a que no ha sido posible asociarla aún con ninguna prenda o función determinada. Retornaré a ella cuando analice con más detalle las técnicas estructurales empleadas para lograr efectos decorativos en los textiles.

De acuerdo a Emery (1966), la estructura de un tejido es la relación espacial y numérica entre los elementos que lo conforman, siendo un elemento la parte componente o unidad constitutiva de un

lana de las especies mencionadas. Al respecto, los resultados de los análisis de isótopos sobre fibras procedentes de la tumba de PP9 aportan datos adicionales para confirmar la presencia tanto de especies salvajes como domesticadas, en base a las diferencias observadas para los componentes de la dieta de cada grupo de fibras (Macko et al. 2001). tejido. Un grupo de componentes que es usado tendiendo todos en idéntica dirección y cumpliendo la misma funcionalidad, constituye un grupo de elementos. La forma más simple de tejido está hecha por dos grupos de elementos que intertrabajan para formar la tela. Un primer grupo de elementos se extiende en el telar en forma longitudinal y recibe el nombre de urdimbres. El segundo grupo de elementos ocupa en el telar la posición transversal y es lo que se conoce con el nombre de tramas. La forma en que se clasifican las diferentes estructuras de un tejido se basa en la disposición, es decir, el orden y la forma en que los grupos de elementos se relacionan e intertrabajan para formar los tejidos.

En el caso de la muestra aquí analizada, todos los especímenes corresponden al tipo de estructura conocida con los nombres de "tejido simple", "tejido plano" o "llano" ("plain weave" sensu D'Harcourt 1977). La estructura de tejido llano es la forma más elemental y básica de tejido. Los hilos de la urdimbre y de la trama se presentan regularmente entrecruzados, de esta manera, las dos caras del tejido son iguales. Esta estructura de tejido presenta, a su vez, dos tipos, según las relaciones de densidad (o espaciado) entre los elementos de urdimbre y de trama. La casi totalidad de las prendas funerarias de PP9 están construidas en el tipo denominado faz de urdimbre ("warp faced", "reps de urdimbre" o "urdimbre vista", sensu Gisbert et al. 1987) (Cuadro 1). Es decir, que presentan un número mayor de urdimbres que 
SARA M. L. LOPEZ CAMPENY

\begin{tabular}{|l|c|c|l|c|c|l|c|c|}
\hline FORMAS & $\mathbf{N}^{\mathbf{0}}$ & $\boldsymbol{\%}$ & MATERIA PRIMA & $\mathbf{N}^{\mathbf{o}}$ & $\boldsymbol{\%}$ & ESTRUCTURA TEXTIL & $\mathbf{N}^{\mathbf{0}}$ & $\%$ \\
\hline Chuspa & 1 & 5.55 & Fibra camélido & 18 & 100 & Faz de Urdimbre & 17 & 94.45 \\
Unku & 1 & 5.55 & Fibra vegetal & - & - & Faz de Trama & 1 & 5.55 \\
Manta & 1 & 5.55 & Algodón & - & - & & \\
Bolsa funeraria & 2 & 11.10 & & & & & & \\
Faja & 1 & 5.55 & & & & & & \\
Indeterminadas & 12 & 66.70 & & 18 & 100 & TOTAL & 18 & 100 \\
\hline TOTAL & 18 & 100 & TOTAL & & & & \\
\hline
\end{tabular}

Cuadro 1. Forma, técnica y materia prima de los textiles de PP9.

de tramas por unidad de medida, lo que implica un menor espaciado de sus elementos en relación con la trama. El nombre de faz de urdimbre se debe a que estos elementos son los únicos que quedan visibles en ambas caras del tejido, ya que se encuentran tan apretados entre sí que ocultan completamente a los elementos de la trama. El efecto resultante es que la tela presenta un relieve o acanalado transversal, en el sentido de la trama. Sólo los dos fragmentos que hemos vinculado tentativamente con una faja o vincha, presentan una estructura de tejido llano en faz de trama, es decir, que presentan un mayor número de tramas por unidad de medida, debido al menor espaciado de sus elementos en relación con las urdimbres. Estos dos fragmentos también pueden ser designados con el nombre de tapices, ya que los diseños decorativos se formaron mediante cambios de color de los elementos de trama. En la técnica de tapicería la trama juega el papel activo y es visible en ambas caras del tejido, siendo los diseños idénticos en el anverso y el reverso de la tela. La particularidad de la tapicería consiste en que la trama no cruza de manera ininterrumpida todo el ancho del tejido, sino que varios hilos, de distintos colores, abarcan diversos tramos de la urdimbre, entretejiéndose únicamente con la urdimbre correspondiente a un determinado sector, avanzando y retrocediendo para conformar los diseños decorativos. Por este motivo, esta modalidad dentro del tejido en faz de trama, también recibe el nombre de técnica de tramas discontinuas. Si bien permite a la tejedora un manejo mucho más libre del diseño que la técnica de faz de urdimbre, en la textilería andina meridional ha primado en forma notable la técnica de faz de urdimbre (Gisbert et al. 1987).

A su vez, dentro de cada uno de estos dos tipos principales de estructura, existe lo que se deno- minan variedades. Pero, teniendo en cuenta que estas variedades han sido empleadas fundamentalmente con la finalidad de conformar los diseños decorativos de las telas, me referiré a ellas más adelante, cuando analice este aspecto de las prendas textiles.

Sobre las características de los hilados que conforman las estructuras textiles

A continuación, efectué una descripción completa de los hilos que participan en el tejido como elementos de la estructura, es decir, como elementos de trama o de urdimbre. Los hilos correspondientes a costuras de unión, decorativas, bordados, etc., fueron analizados como elementos superestructurales. Para llevar a cabo la descripción he seguido la misma metodología adoptada para el análisis de la cordelería, consignándose los datos correspondientes a diámetro, dirección de hilado, torsión y retorsión, ángulo de torsión, número de segmentos por $\mathrm{cm}$, tipo de tensión, tipo de hilado y color (López Campeny 2001a).

Una observación que se desprendió del análisis consiste en la posibilidad de distinguir a los elementos de trama de los de urdimbre por su diámetro y por su tensión. Considerando los elementos estructurales de una misma pieza, en casi todos los casos, los hilos utilizados como trama son de mayor diámetro y presentan tensión más floja que los hilos utilizados para el montaje de las urdimbres. Considero que esta distinción obedece a una razón de tipo tecnológica. Los hilos de la urdimbre deben ser necesariamente más resistentes y fuertes que los utilizados como elementos de trama, ya que deben sufrir la tensión permanente al ser estirados para el montaje en el telar y los continuos roces producidos por las sucesivas pasadas de los hilos de trama. Por esta razón, para 
ofrecer una mayor resistencia a los esfuerzos, los hilos de la urdimbre deben ser más delgados y presentar un mayor número de torsiones por unidad de medida que los hilos de la trama.

También he podido observar que todos los hilados utilizados como elementos de urdimbre son monocromos, aunque la única excepción lo constituyen los dos fragmentos de tapicería, que presentan hilados de urdimbre moliné. ${ }^{11}$ Lo destacable es que estos corresponden a los dos únicos fragmentos de una pieza confeccionada en faz de trama. En el resto de las piezas textiles de la tumba, confeccionadas todas en faz de urdimbre, fue común registrar la utilización de hilados moliné, pero siempre como elemento de trama. En otros términos más simples, esta característica recurrente de los hilados pareciera indicar una clara selección de los hilos de acuerdo a su visibilidad en el tejido: hilados monocromos para los elementos visibles, e hilados moliné para los elementos de la estructura que quedan ocultos al observador de la prenda.

Dos tipos de hilados, a los que he definido como hilados jaspe je $^{12}$ mismido ${ }^{13}$ se limitan exclusivamente a dos de las piezas textiles: al unku y a la manta. También en este caso creo que existe una clara selección de un tipo especial de hilados por una razón de tipo funcional. Se trata de hilados

11 Corresponden a aquellos cordeles que presentan hilos de, al menos, dos colores diferentes lo que produce efectos de color en el tejido. La definición puede hacerse extensiva a hilados que emplean dos materias primas diferentes, lo que produce efectos decorativos por textura. En el caso de los textiles aquí analizados sólo hemos registrado hilados moliné por efecto de color.

12 El término jaspe lo tomo de Ulloa (1974: 76), aunque con leves modificaciones, para referirme a aquellos cordeles que presentan la torsión conjunta de tres cabos, que se logran torsionando primero dos hilos relativamente delgados, los cuales a su vez retuercen a un tercer hilo más grueso y con un hilado mucho más suelto. Esto da como resultado un cordel de un diámetro bastante irregular y variable en su longitud, lo que produciría efectos decorativos por textura. En todos los casos registrados aquí, los hilados jaspes son además moliné, ya que el tercer hilo es de un color diferente al de los dos primeros hilos (López Campeny 2001a: 168).

13 Los hilados mismido reciben este nombre debido a que están confeccionados con una mismina o palo de hilar, que es un huso, pero sin tortera. Como resultado los hilos producidos son muy gruesos, de un diámetro muy irregular o variable y de un torcido no muy fuerte (Rolandi de Perrot y Jiménez de Pupareli 1985: 226-228). muy gruesos, los que han sido utilizados para la confección de prendas que debieron cumplir con la función de abrigar. Si bien las prendas no pueden definirse estrictamente como una manta o como una túnica "felpuda", por no exhibir este efecto de textura debido a la ausencia de pelos o mechones de lana que sobresalgan de la superficie (hilado bouttonné, sensu Agüero 1995), no puedo dejar de mencionar que las dos piezas presentan una textura "gruesa" que recuerda a este tipo de prendas formativas transandinas. Este efecto grueso o "mullido" es el producto de los hilos mismido que forman la estructura de las urdimbres. Respecto a estas coincidencias morfológicas y técnicas son sugerentes los datos que, vinculados a su funcionalidad en relación con contextos funerarios, menciona Renard al referirse a estas prendas:

"La modalidad de tejidos con pelos en superficie se ha aplicado a la confección tanto de mantas como de túnicas. Además de la función que pudieron tener en vida de sus usuarios, este tipo de tejido se utilizó para envolver a los muertos al ser enterrados. Estuvieron en uso durante un prolongado período de tiempo, desde el Formativo hasta épocas tardias” (Renard 1997: 300).

Para el sitio Topater-1, Sinclaire (1997: 331) menciona la presencia de fardos funerarios cubiertos con mantas felpudas de forma rectangular, decoradas con listados y tejidas con hilados muy gruesos. También Agüero y Cases (2000) resaltan como un atributo frecuente de las mantas y túnicas procedentes de contextos funerarios formativos (Tarapacá-40, Topater-1, San Pedro de Atacama) el efecto grueso o mullido de las prendas. En ambas prendas de PP9 he detectado, además, el empleo de un número elevado de hilos de trama. Seis tipos diferentes en la túnica y once tipos diferentes de hilos de trama en la manta, mientras que el resto de las piezas tejidas en faz de urdimbre utilizan, para su confección, una única trama continua. La utilización de tramas múltiples se hace de una manera no regular, combinando la utilización de tres, cuatro y hasta cinco tramas alternadas en diferentes sectores de ambas piezas (Figura 6). El empleo de tramas múltiples en la confección de túnicas es señalado como un rasgo técnico estructural bastante frecuente en piezas textiles recuperadas en sitios del noroeste y centro argentino, por ejemplo Doncellas (Rolandi de Perrot 1979), Tastil (Rolandi de Perrot 1973), Loro 


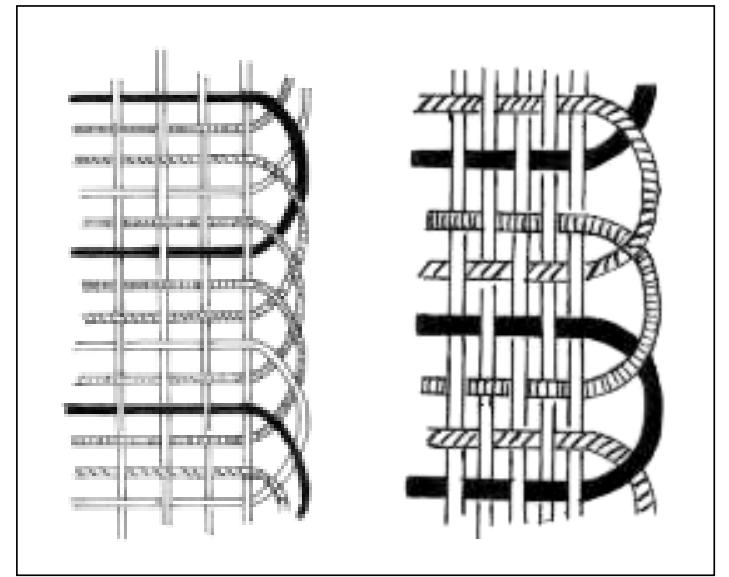

Figura 6. Empleo de tramas múltiples.

Huasi y Angualasto (Renard 1997). Esta técnica también aparece como un atributo frecuente en la confección de las mantas felpudas recuperadas en diferentes sitios arqueológicos del norte chileno (Mostny 1952, Agüero 1995, Agüero y Cases 2000).

Por último, los dos fragmentos de tapicería, únicos ejemplares construidos en faz de trama, muestran la utilización de dos colores de hilos de trama, los que recorren el espacio del tejido en forma discontinua con la finalidad de formar los diseños decorativos geométricos.

Con respecto a otra característica, la dirección de torsión de los hilados, tomo de Agüero (1994) el dato de que la torsión inversa (sZ) de los hilos es un hecho raro y poco frecuente entre los textiles documentados para el norte de Chile, así como también en los hilados arqueológicos de la costa sur peruana. En cambio, la llamada torsión zurda es un atributo más común en la costa central pe- ruana, llegando al caso de que en la costa norte del Perú la totalidad de los hilados se tuercen hacia la izquierda (sZ). Basándose en estos datos la autora opina que

“(...) el hilar y el torcer hacia un lado u otro constituye una elección cultural y que en los Andes representa un indicador del lugar geográfico de su manufactura” (Agüero 1994: 117).

Coincido con la interpretación anterior y añado aquí otras evidencias con respecto a la predominancia de la dirección final de torsión derecha en la textilería de los Andes Meridionales. He registrado entre las piezas de PP9 un total dominio de los hilados zS en los elementos de la estructura textil formados por cordeles de dos cabos. Además, los cordeles presentes en la estructura del tejido con una única dirección de hilado, como por ejemplo los hilados mismido que no presentan torsión (hilado de un solo cabo), muestran una dirección de hilado S (Cuadro 2). Es decir, que lo que podemos observar es una dirección final de torsión predominante: la torsión $\mathrm{S}$ o derecha. Esto queda atestiguado en el hecho de que si el cordel es de dos cabos, entonces el hilado es $\mathrm{Z}$ y la torsión es $\mathrm{S}$, pero si el hilo utilizado presenta un solo cabo, entonces el hilado es en S. Es por haber detectado esta tendencia general, que ha retenido mi atención la identificación de un hilo con torsión inversa (sZ), que presenta hilado moliné en amarillo ocre y negro, formando parte de la manta. Me ha resultado notable por dos motivos. En primer lugar porque este sería, dentro de la muestra analizada, el único ejemplo de un hilo moliné que queda visible en un tejido. A eso se suma el hecho de ser el único hilo registrado con torsión inversa. Se trata de un

\begin{tabular}{|c|c|c|c|c|c|c|c|c|}
\hline HILADOS & $\mathbf{N}^{\mathbf{o}}$ & $\%$ & TRAMAS & $\mathbf{N}^{\mathbf{o}}$ & $\%$ & DIRECCION TORSION & $\mathbf{N}^{\mathbf{o}}$ & $\%$ \\
\hline Urd. Monocromo & 17 & 94.45 & Tramas continuas & 16 & 88.9 & $\mathrm{Z}$ & - & - \\
\hline Urd. Moliné & 1 & 5.55 & Tramas discontinuas & 2 & 11.1 & $\mathrm{~S}$ & 2 & 11.1 \\
\hline Total & 18 & 100 & Total & 18 & 100 & $\mathrm{ZS}$ & 16 & 88.9 \\
\hline Simple & 18 & 62 & Trama única & 16 & 88.9 & sZ & - & - \\
\hline Jaspe & 2 & 6.95 & Tramas múltiples & 2 & 11.1 & & & \\
\hline Mismido & 2 & 6.95 & & & & & & \\
\hline Moliné & 7 & 24.10 & & & & & & \\
\hline TOTAL & 29 & 100 & TOTAL & 18 & 100 & TOTAL & 18 & 100 \\
\hline
\end{tabular}

Cuadro 2. Relación de tipos de hilados, tramas y dirección de la torsión. 


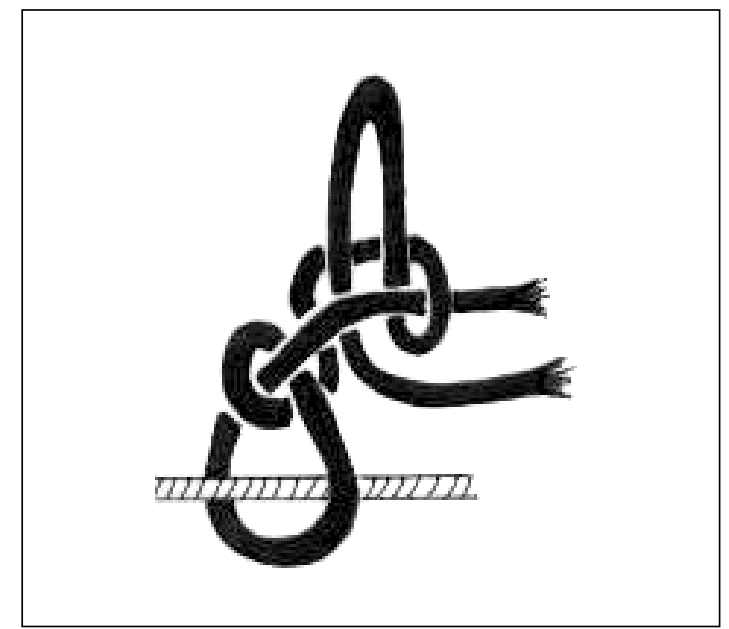

Figura 7. Esquema de nudo en lazo confeccionado con hilo moliné.

cordel que presenta un nudo central y un doble lazo. Uno de los lazos se une a la penúltima línea de trama, el otro lazo queda libre sobre el borde de urdimbre de la manta, por debajo de una cadeneta decorativa terminal (Figura 7). Para explicar este ejemplo necesito recurrir a otro aspecto relacionado con la dirección de torsión, una dimensión que va más allá de la localización geográfica del hallazgo y que se relaciona con el universo mágico y ritual. Por lo tanto, me extenderé sobre el aspecto ritual de la torsión zurda o izquierda en el apartado correspondiente a este aspecto de los textiles.

Respecto de las técnicas decorativas estructurales utilizadas

Un pequeño grupo de las piezas recuperadas en el contexto funerario utiliza alguna, o más de una, técnica decorativa estructural (Cuadro 3). Es de- cir, que presentan, dentro de los dos tipos de estructuras principales identificados (faz de urdimbre y faz de trama), alguna variedad de técnica que ha sido empleada con la finalidad de lograr efectos decorativos en la prenda. Se denominan técnicas estructurales porque la conformación de la decoración se efectúa mientras la tela es tejida, interviniendo con esta finalidad alguno, o los dos grupos de elementos principales de un tejido: la urdimbre y la trama. Las técnicas estructurales decorativas que he podido identificar son:

Listado en faz de urdimbre. Esta técnica se concibe a partir del montaje de las urdimbres en el telar y se basa en la diferenciación, por color, de los hilos de la urdimbre. Las bandas o listas, que constituyen la base de esta decoración, se logran con pares de hilos del mismo color que se colocan agrupados, para generar un área longitudinal de un determinado color. Cuanto mayor es el número de urdimbres de cada color, más ancha es la banda. La alternancia o cambio de color de las listas se consigue al cambiar, cada determinado espacio, el color de los pares de hilos de la urdimbre. De acuerdo con O'Neale (1932, cit. en Rolandi de Perrot 1973: 298-299) el empleo de la decoración listada en faz de urdimbre implica una concepción del diseño antes de ser tejida la pieza: los colores deben ser escogidos y ordenados durante el procedimiento de urdido, lo que implica una mayor experiencia que la elaboración de diseños a partir de la estructura de trama. Dos piezas de PP9 presentan decoración listada en diferentes tonos naturales de castaño. En la primera (la manta), el efecto decorativo se logra principalmente por un efecto de contraste, ya que las listas adyacentes presentan tonos claros y oscuros en contacto. En la segunda (el unku), en cambio,

\begin{tabular}{|c|c|c|c|c|c|c|c|c|}
\hline ESTRUCTURA DECORATIVA & $\mathbf{N}^{\mathbf{o}}$ & $\%$ & VARIEDADES & $\mathbf{N}^{\mathbf{o}}$ & $\%$ & MOTIVOS & $\mathbf{N}^{\mathbf{o}}$ & $\%$ \\
\hline $\begin{array}{l}\text { Faz de urdimbre } \\
\text { Faz de trama } \\
\text { Sin decoración }\end{array}$ & $\begin{array}{c}5 \\
1 \\
12\end{array}$ & $\begin{array}{c}27.7 \\
5.6 \\
66.7\end{array}$ & $\begin{array}{l}\text { Listado faz urd. } \\
\text { Urd. transpuestas } \\
\text { Peinecillos } \\
\text { Urd. torsionadas } \\
\text { Urd. flotantes } \\
\text { Flecos estructur. } \\
\text { Tapiz }\end{array}$ & $\begin{array}{l}2 \\
1 \\
1 \\
1 \\
1 \\
1 \\
1\end{array}$ & $\begin{array}{c}25 \\
12.5 \\
12.5 \\
12.5 \\
12.5 \\
12.5 \\
12.5\end{array}$ & $\begin{array}{l}\text { Listas lisas } \\
\text { Rombos } \\
\text { Líneas segmentadas } \\
\text { Escalerado superp. } \\
\text { Líneas quebradas } \\
\text { Triángulos }\end{array}$ & $\begin{array}{l}2 \\
1 \\
1 \\
1 \\
1 \\
1\end{array}$ & $\begin{array}{l}28.5 \\
14.3 \\
14.3 \\
14.3 \\
14.3 \\
14.3\end{array}$ \\
\hline TOTAL & 18 & 100 & TOTAL & 8 & 100 & TOTAL & 7 & 100 \\
\hline
\end{tabular}

Cuadro 3. Estructura decorativa, variedades y motivos. 
los tonos adyacentes son similares y los colores se oscurecen progresivamente hacia el centro, el que actúa como elemento de simetría, reiniciándose nuevamente la serie de colores. A su vez, en ambas piezas, la distribución de los colores de las bandas se ordenan de acuerdo con un esquema de simetría axial, de tipo bilateral e imagen especular. Esta técnica decorativa aplicada a la manta de PP9, sumada a las propiedades ya mencionadas de los hilados que la conforman, coinciden con las numerosas mantas recuperadas como parte de ajuares mortuorios en contextos formativos del Norte Grande de Chile, cuyas

“(...) soluciones decorativas (...) se reducen exclusivamente a las listas o a diferencias en la torsión de los hilados para producir efectos de textura" (Horta $2000 \mathrm{Ms}$ ).

Urdimbres transpuestas. Esta designación es tomada por Rolandi de Perrot de Mahler, quien la define de la siguiente manera:

"Transposed warp pattern: the warps temporarily are shifted from their normal vertical position, one o more places to the right or left, thus showing diagonally on the cloth" (Mahler 1959: 65, cit. en Rolandi de Perrot 1973: 325).

Es decir, como aquella técnica en la que algunos elementos de la urdimbre son desplazados o alzados de su posición original para trasladarlos uno o más lugares hacia la derecha o hacia la izquierda. Cuando son transportados, los hilos de la urdimbre quedan ocultos por la trama, volviendo a aparecer en el tramo donde participan o son requeridos de acuerdo a la configuración del diseño. Generalmente esta técnica ha sido utilizada para la realización de motivos decorativos con figuras romboidales o diseños que, en términos generales, presentan líneas diagonales; ya que este es el efecto que se consigue al transponer, de una pasada a la otra, la posición original de la urdimbre. Así por ejemplo, esta técnica fue usada ampliamente en la decoración de algunos de los textiles recuperados en los sitios de Tastil y Doncellas, para conformar diseños de ' $\mathrm{V}$ ' en zigzag, en los laterales de prendas como unkus (Rolandi de Perrot 1973 y 1979). Un punto que me parece relevante destacar en relación con esta técnica es que, al parecer, se trataría de un rasgo peculiar del área andina meridional. De acuerdo con los datos arqueológicos que se manejan hasta la fecha, esta técnica parece haber sido utilizada en un área geográfica muy limitada, acotada a los sectores norte y oeste de los actuales países de Argentina y Chile (Rowe 1977: 104, Rolandi de Perrot 1979, Renard 1999: 88). El textil recuperado en PP9 que presenta esta técnica es la pequeña pieza rectangular que se encontró cosida, por medio de un cordel de cabello humano, a una de las bolsas funerarias (Figura 8). La transposición de urdimbres se ha empleado de una manera muy particular, sobre la que no hemos encontrado antecedentes de hallazgos similares. La pieza presenta, en su sector central, un campo decorado con pequeños rectángulos de dos tonos contrastantes, alternados de manera que conforman un diseño en damero (peinecillos). Hacia arriba y hacia abajo de este diseño de peinecillos se disponen figuras romboidales, para cuya conformación se ha utilizado la técnica de desplazamiento de las urdimbres (Figura 9). La originalidad en la forma de transponer las urdimbres consiste en que todos los hilos se desplazan en una forma muy

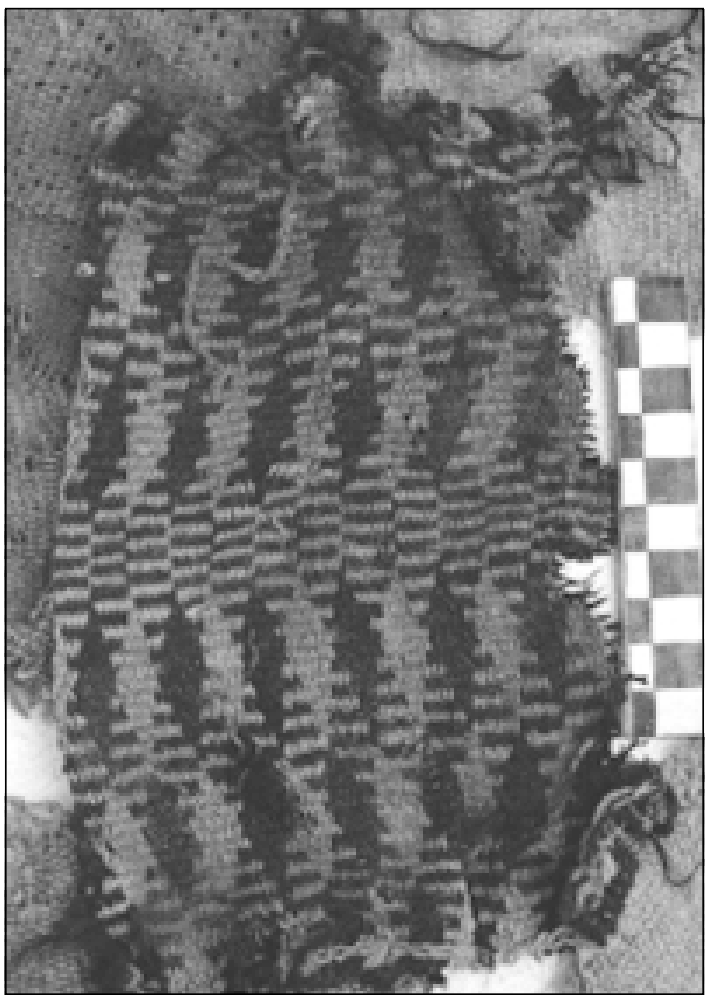

Figura 8. Tela decorada con la técnica de urdimbres transpuestas. 


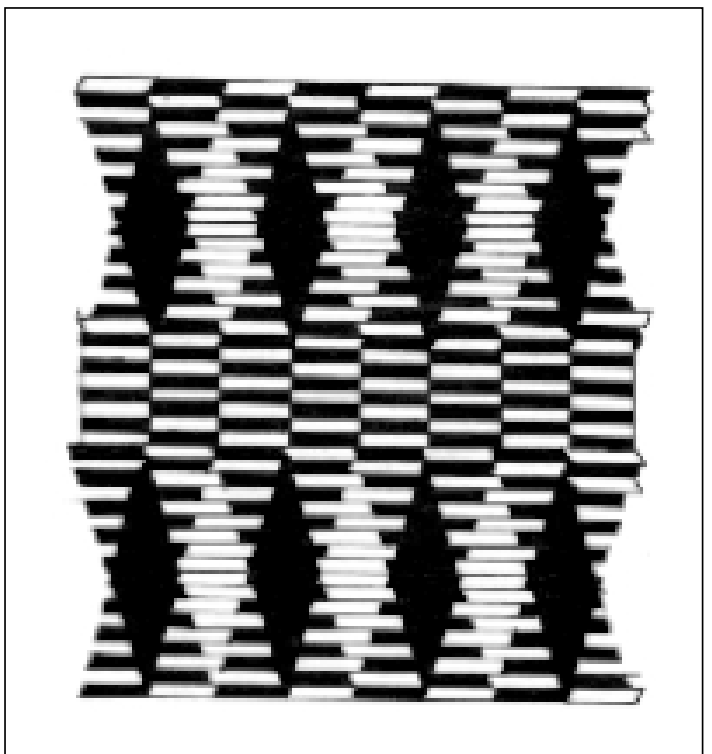

Figura 9. Diseño decorativo de la pieza rectangular con urdimbres transpuestas.

regular y repetitiva pero, a diferencia de la técnica tradicional, las urdimbres nunca retornan nuevamente a su posición original, sino que se desplazan sucesivamente, sin cambiar nunca de dirección, hasta llegar a los orillos de trama. Las urdimbres de una pasada lo hacen siempre un lugar hacia la izquierda, y las que reaparecen en la siguiente pasada se desplazan continuamente un lugar hacia la derecha (Figura 10). Por lo anterior, considero que el término urdimbres divergentes puede ser más adecuado que el de transpuestas para describir el movimiento de estos elementos en la tela. La forma en que se organiza el diseño, con un patrón de urdido simétrico respecto al centro del tejido, recuerda a la técnica de sprang. Sin embargo, considero que no es correcto utilizar este término creando confusión, ya que el sprang se construye con un solo conjunto de elementos (urdimbres), mientras que la pieza que aquí refiero presenta elementos de trama y urdimbre. A pesar de esto, la forma básica de construcción de la prenda parece haber sido la misma que en el sprang, iniciándose el tejido en los bordes y terminando en el centro de la pieza. Por lo antes mencionado, y siguiendo la sugerencia de Frame (com. pers. 2001), el nombre más indicado para la técnica empleada en la confección de esta pieza sería el de "técnica recíproca con dos elementos y urdimbres divergentes".

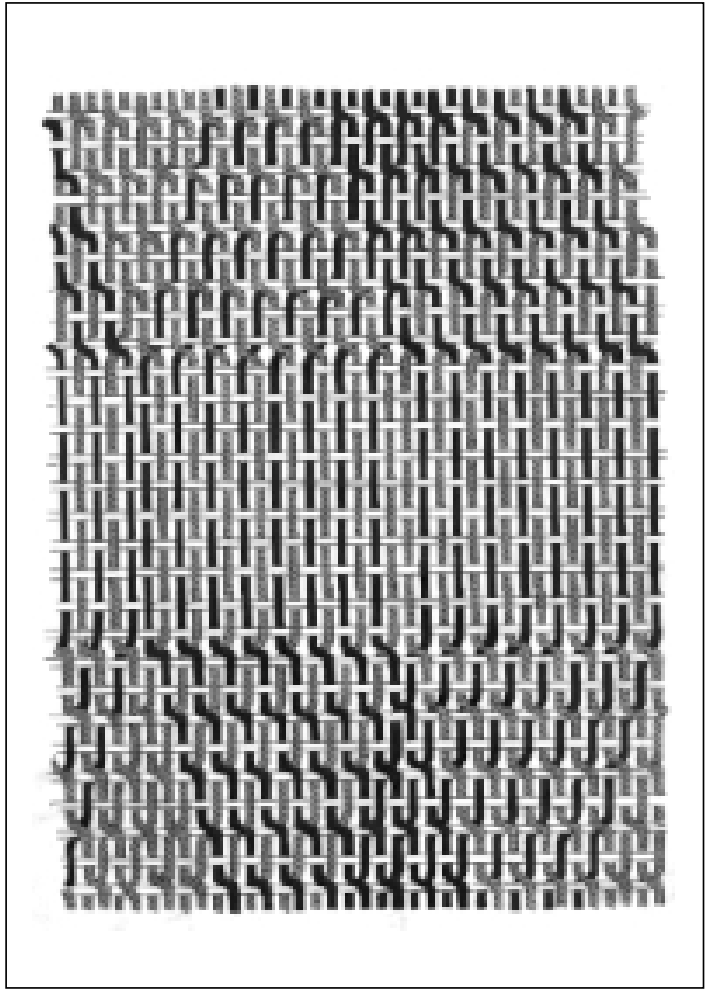

Figura 10. Modalidad de la técnica de urdimbres transpuestas.

Peinecillos. Esta técnica consiste en que los hilos de la urdimbre se ponen en pares, pero de colores diferentes, es decir que el hilo, en vez de urdir un giro completo, hace medio giro y alterna medio giro con un hilo de otro color. El efecto resultante que se produce al tejer es una hilera horizontal de un color y la siguiente de otro, y así alternativamente. Los peinecillos se caracterizan por tener un número limitado de entre cuatro y diez pares de dos colores, ya que si se utilizara el mismo color de manera ininterrumpida el resultado decorativo serían líneas transversales y no peinecillos. Después de tejer este número limitado de pares se cambian los colores o se invierte la posición, de modo que la serie alterne en cada pasada de trama. El resultado que se obtiene es una superficie con pequeñas líneas horizontales cortas, formando un diseño con colores alternados de estilo damero (Figura 11). En relación con el diseño de peinecillos, Sinclaire (2001) menciona que ha sido documentado en forma frecuente en la iconografía textil formativa del norte de Chile, formando parte de la decoración de túnicas, fajas y huinchas confeccionadas en telar. 
Como acabamos de mencionar esta técnica decorativa es empleada para conformar el sector central de la pieza rectangular unida a la bolsa funeraria. Este diseño en dameros constituye el motivo respecto al cual se repite en forma simétrica, hacia arriba y hacia abajo, el diseño de rombos en positivo y negativo, logrado por la divergencia de las urdimbres y la alternancia de los dos colores básicos de estos elementos. También en el caso de esta prenda la construcción de la decoración se consigue a través de la utilización de principios de simetría bilateral.

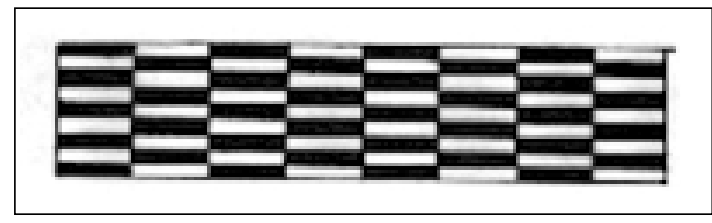

Figura 11. Diseño estructural de peinecillos.

Urdimbres torsionadas simples. ("warp twining" sensu Emery 1966, "twisted warp" sensu D'Harcourt 1977, urdimbres torcidas sensu Gisbert et al. 1987, torzal sensu Brugnoli y Hoces de la Guardia 1998). En esta estructura, los hilos de urdimbre contiguos están torsionados juntos, de a pares. La trama es envuelta por la torsión de los hilos y queda, de esta manera, sujeta entre los giros de los pares. Por lo tanto, la trama pasa a través de estos torzales, dejando urdimbres tanto por encima como por debajo de ellas (Figura 12). Según Gisbert y colaboradores (1987), una característica de esta técnica es que, a medida que se va tejiendo la pieza, los hilos de la urdimbre van torciéndose más y más, creando dificultad para la inserción de la trama. En opinión de D'Harcourt (1977), este problema pudo haberse solucionado al tejer la prenda comenzando simultáneamente en los dos extremos y finalizando en el centro. Al tejer la pieza en uno de los extremos, la torsión de los hilos de urdimbre produciría una torsión en sentido contrario de los hilos del otro extremo. La pieza que presenta la utilización de urdimbres torsionadas es la pequeña bolsa o chuspa. ${ }^{14} \mathrm{El}$ motivo decorativo dominante en la mayor parte de la tela es simétrico con respecto a otro diseño, levemente diferente, ubicado en el doblez correspondiente al fondo de la bolsa, por lo que su forma de construcción puede corresponderse con la descrita para la pieza rectangular con peinecillo y

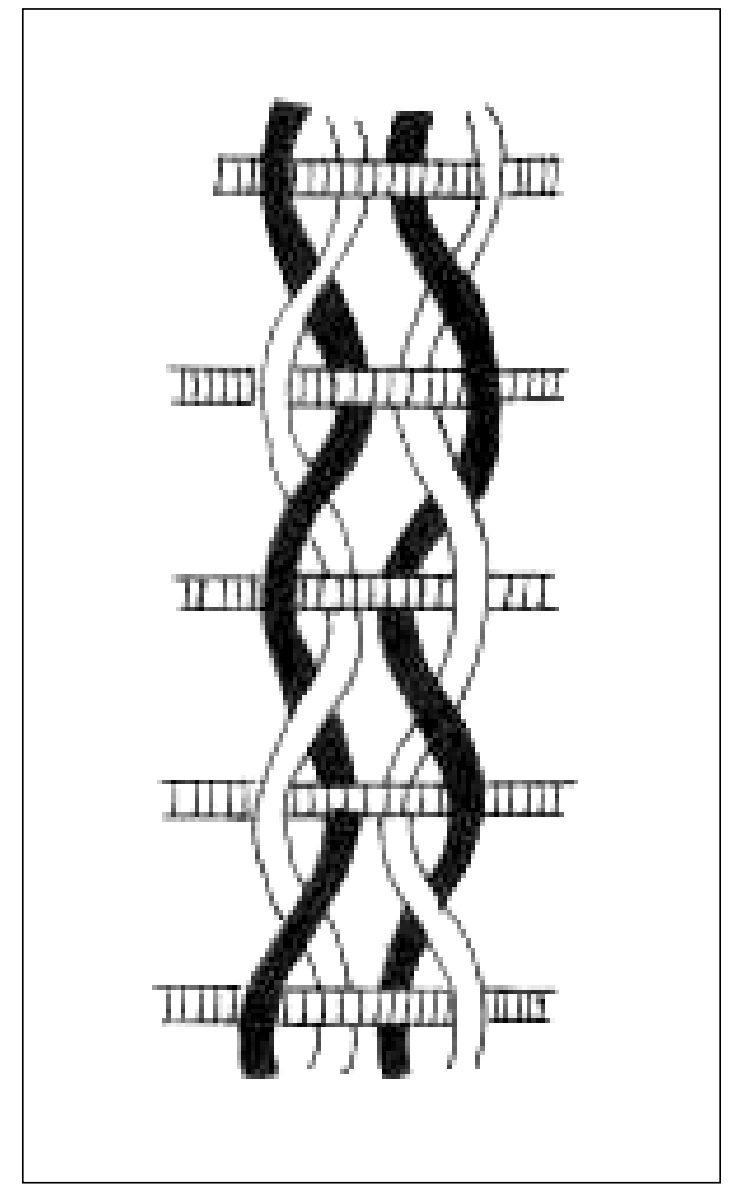

Figura 12. Urdimbres torsionadas.

urdimbres divergentes. Es decir, que la pieza se tejió iniciándose en los extremos y culminando en el centro. Esto ha sido comprobado mediante la observación de que los hilos de las urdimbres presentan, en cada uno de los extremos del tejido, direcciones opuestas de inclinación. Por lo tanto, también en este caso es adecuado designar a la forma de construcción de esta pieza como una "técnica recíproca de dos elementos con urdim-

14 Es necesario aclarar que en un trabajo anterior (López Campeny 2001c), hice referencia a que la técnica empleada para lograr la configuración de los diseños en esta pieza era la de urdimbres transpuestas. Una posterior observación de la pieza, más detallada, me permitió notar que las urdimbres están torsionadas y que lo que había sido interpretado como transposición de urdimbres corresponde a la separación de las urdimbres pareadas monocromas y la modificación de su recorrido para torsionarse con elementos del segundo color. 
bres torsionadas". El motivo decorativo principal de la chuspa consiste en una serie de escalonados superpuestos y continuos, formados por líneas rectas quebradas. En el sector central del tejido, la figura básica del escalerado se amplía y encierra en su interior una serie de cortas líneas que alternan los dos colores principales en un diseño que recuerda a los peinecillos (Figura 13). El análisis de la pieza me permitió notar que los dos colores empleados para conformar el diseño no se invertían, entre una y otra faz, en los tramos verticales (sentido de las urdimbres). Esta característica del tejido sólo podía explicarse por el empleo de urdimbres torsionadas de a pares, con ambos elementos de igual color en cada cara de la tela. Sin embargo, en los tramos horizontales (sentido de las tramas), los colores sí mostraban inversión entre una y otra faz del tejido. He podido notar que, si bien las urdimbres se han montado torsionadas en pares de idéntico color, cuando la conformación del diseño lo requiere, las urdimbres pareadas se separan, modifican el recorrido

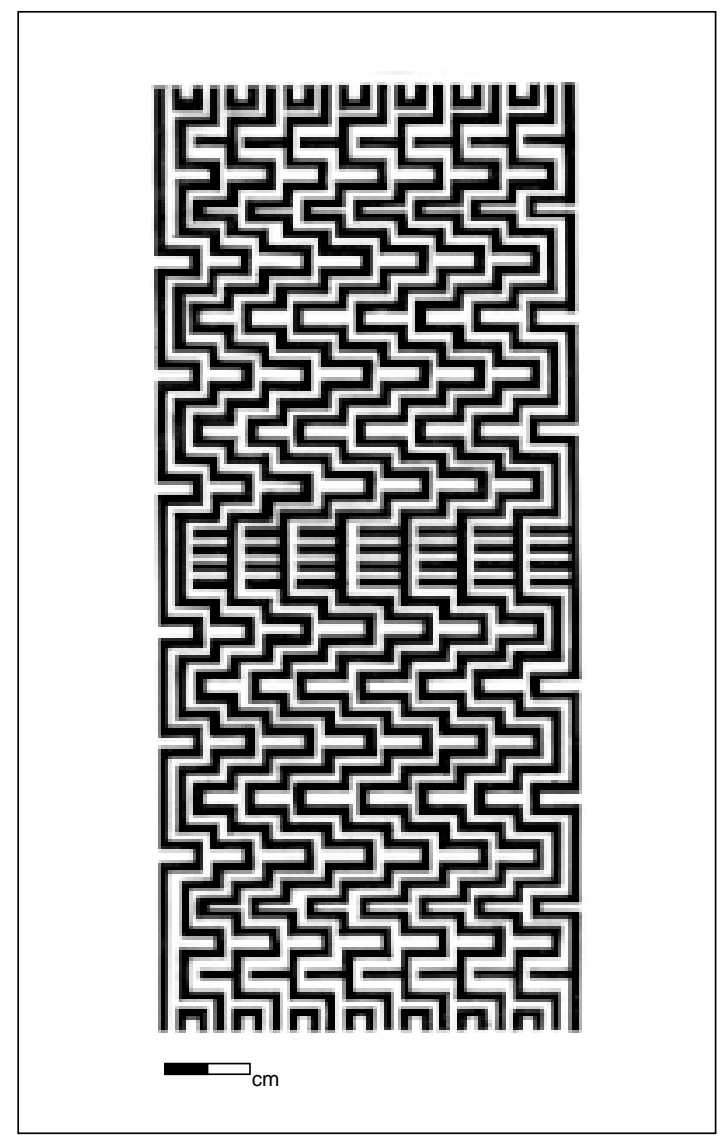

Figura 13. Diseño decorativo de la chuspa desplegada. y se torsionan con un elemento correspondiente al segundo color, para formar de esta manera el diseño de escalonados superpuestos.

Urdimbres flotantes. La técnica consiste simplemente en que los hilos de urdimbre saltan más de uno de los elementos de trama correspondientes, lo que se realiza con el propósito de crear efectos decorativos en el tejido. La utilización de urdimbres flotantes sólo se ha detectado en la chuspa y ésta ha sido utilizada en los dos colores de urdimbre que forman los diseños decorativos. Los hilos saltan dos elementos de trama en algunos sectores donde la conformación del diseño lo requiere.

Flecadura estructural. Dos fragmentos de telas lisas de color marrón oscuro, que no he podido vincular con ninguna prenda específica, han conservado una terminación decorativa en uno de los orillos de urdimbre consistente en una flecadura estructural. La forma de elaboración de estos flecos consiste en la retorsión conjunta (z s 5Z), luego de la última pasada de trama, de cinco elementos de la urdimbre que se han dejado sin tejer en el tramo final (Figura 14). Se forma de esta manera una flecadura continua en el borde termi-

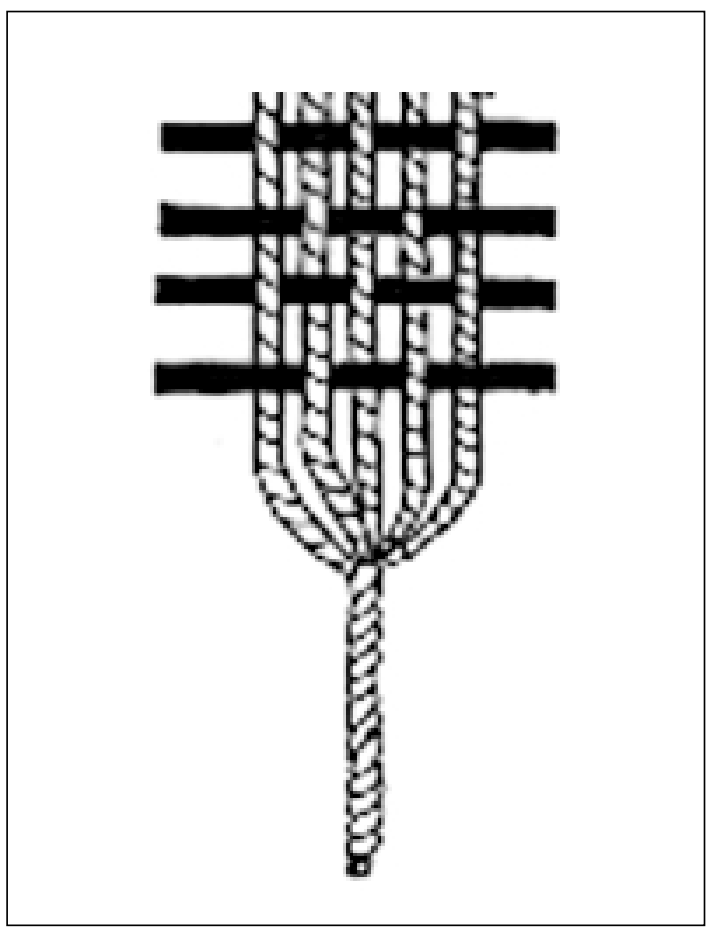

Figura 14. Flecadura estructural. 
nal de la pieza. Este tipo de técnica decorativa se encuentra tempranamente presente en el registro textil del N.O.A., tanto en la puna (como es el caso que aquí presentamos) como en la selva de montaña (tal es el caso de los hallazgos en Las Pirguas). En efecto, en las cercanías de Pampa Grande (Provincia de Salta), González (1983) registra la presencia de entierros en abrigos rocosos con una importante muestra de textiles. El autor adscribe los entierros a lo que se conoce como Candelaria y ubica a algunos de estos hallazgos, radiocarbónicamente, entre el 500 y 550 DC (González 1983: 254). Entre algunos de los atributos técnicos decorativos presentes en esta muestra, Rolandi de Perrot y Nardi (1978: 13) destacan “... la presencia de flecos estructurales formados por las urdimbres libres en un extremo y torsionadas."

Tapicería. Como ya he mencionado, la particularidad de la tapicería consiste en que la trama no cruza de manera ininterrumpida todo el ancho del tejido, sino que varios hilos de trama, de distintos colores, abarcan diversos tramos de la urdimbre, entretejiéndose únicamente con la urdimbre correspondiente a un determinado sector, avanzando y retrocediendo para conformar los diseños decorativos. Existen distintas formas de conectar entre sí los hilos de trama que cruzan las urdimbres, recibiendo la técnica de tapicería diferentes nombres de acuerdo a la forma en que se realiza la unión. Entre la muestra de PP9 se cuentan dos fragmentos de tapices los que, según ciertas características formales, hemos vinculado con una faja, una vincha u otro elemento decorativo similar. La variedad de técnica utilizada es la denomi- nada tapiz entrelazado ("interlocked tapestry"), ya que los dos grupos de hilos de trama principales que vienen de direcciones opuestas, se entrelazan entre sí en el espacio entre los dos hilos de urdimbre contiguos (Figura 15). La técnica se utiliza para crear diseños lineales no figurativos, idénticos en ambas caras los que, debido a las numerosas roturas del tejido, no han podido ser determinados con claridad. Pueden distinguirse parcialmente dos diseños principales: una línea quebrada en ángulo recto y una figura de forma de triángulo isósceles, pero de lados escalonados y base aparentemente recta (Figura 16). No he identificado ningún tipo de simetría en la composición

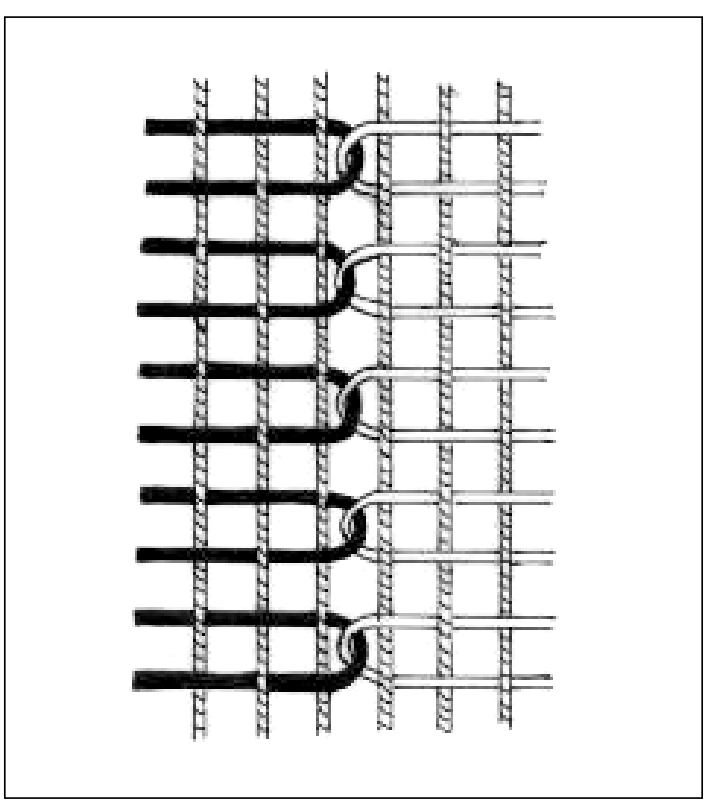

Figura 15. Técnica de tapicería entrelazada.

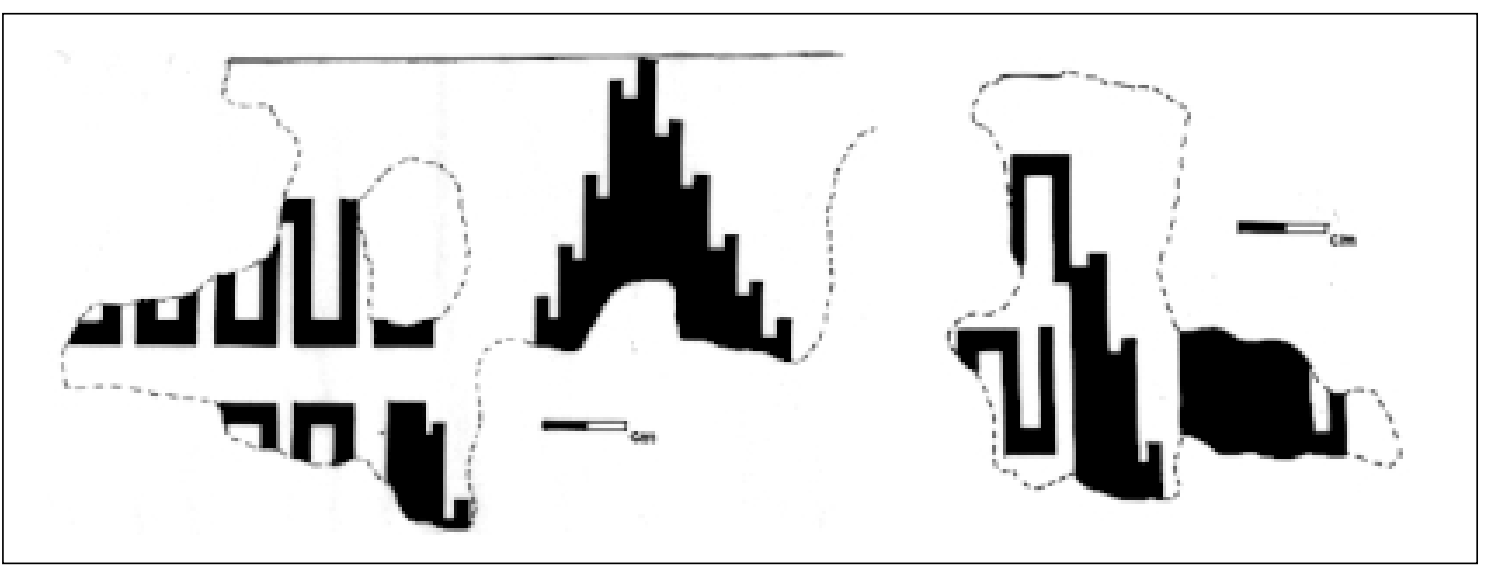

Figura 16. Esquema de los diseños decorativos relevados en los fragmentos de tapicería. 
de la decoración, lo que posiblemente se vincule con la alta fragmentación de la prenda.

Sobre bordes, terminaciones y elementos decorativos superestructurales

También se incluyó en el análisis la observación de los bordes laterales, superiores e inferiores de cada pieza. Consideré relevante analizar los tipos de terminaciones de los orillos de trama (normales, con tramas múltiples, etc.) y la presencia de elementos adicionales tales como costuras decorativas o de unión en cualquiera de los cuatro orillos conservados. Un elemento a destacar, que se desprendió del análisis de los bordes, fue la identificación de la cuerda de telar en la chuspa y en uno de los fragmentos de tela. La denominada cuerda de telar ("heading cords" o "loom strings") es un cordel que se sujetaba por los extremos a los travesaños del telar, luego de que los hilos de la urdimbre se urdieran sobre esta cuerda. Generalmente presenta un mayor diámetro que los hilos que forman parte de la estructura del tejido y a veces, como en estos dos casos, está confeccionada a partir de la retorsión conjunta de varios cordeles idénticos a los que forman la trama o urdimbre del tejido. Frecuentemente, luego de terminado el tejido, los extremos libres de la cuerda eran introducidos en la tela como cualquier pasada de trama, por lo que los tejidos presentaban esta terminación característica de los bordes de urdimbre. En otros casos, como los aquí registrados, la cuerda de telar se ha conservado tomando la posición de primera pasada de trama, al servir como elemento sostén sobre el que se ubican los encabezamientos de las urdimbres y, en el caso de la chuspa, las cuerdas de ambos orillos (superior e inferior) se han unido con dos medios nu- dos en los laterales, para cerrar el borde superior o abertura de la bolsita.

Luego, llevé a cabo una descripción de todos aquellos elementos que no pertenecían a la estructura del tejido, lo que incluyó a todo tipo de costuras (de unión, decorativas o de reparación), bordados, nudos, terminaciones decorativas de los orillos de urdimbre (cadenetas o flecos), cordeles o sogas que cumplían la función de atar o sujetar a los tejidos, cuentas u otros objetos decorativos cosidos a la tela, etc. La descripción de estos elementos abarcó los datos que menciono a continuación. En el caso de costuras y bordados: ubicación (distancia con respecto a los orillos más cercanos, borde de trama o de urdimbre), designación de la costura o bordado (nombre con que se la conoce comúnmente), explicación de su elaboración (lo que incluye un esquema), descripción completa del hilo y medición de la extensión de la puntada (largo y ancho). En el caso de los flecos superestructurales: descripción de la configuración general del fleco y forma de elaboración, descripción del tipo de unión entre los flecos y el borde de la tela (incluye esquema), descripción completa del o los hilos utilizados para la confección del fleco, medición de la extensión de los flecos. Y finalmente, en el caso de la categoría que designo como agregados, procedí a la descripción completa de elementos como cuerdas, adornos, hilos de sujeción de otros elementos, entre otros.

Entre los elementos superestructurales relevados es posible sintetizar la siguiente información (Cuadro 4). Comenzando con las costuras, aquellas que designo exclusivamente como de unión son las que no parecen haber sido realizadas además con fines decorativos, sino solamente con la intención

\begin{tabular}{|c|c|c|c|c|c|c|c|c|}
\hline Punto corrido envuelto & 6 & 35.3 & Contraste color & 5 & 23.9 & Axial & 3 & 12.5 \\
\hline Puntada en borde de urdimbre tipo festón & 3 & 17.7 & Sin efecto & 14 & 66.7 & Especular & 3 & 12.5 \\
\hline Puntada enlazada simple en borde de urdimbre & 1 & 5.86 & & & & $\mathrm{~S} /$ simetría & 1 & 4.2 \\
\hline Cadena de eslabones en borde de urdimbre & 1 & 5.86 & & & & & & \\
\hline Cuenta circular de valva & 1 & 5.86 & & & & & & \\
\hline TOTAL & 17 & 100 & TOTAL & 21 & 100 & TOTAL & 24 & 100 \\
\hline
\end{tabular}

Cuadro 4. Elementos superestructurales, efectos y simetría. 
de unir dos bordes de telas. Este tipo de costuras ha sido relevado en los bordes laterales (orillos de trama) de la manta, el unku, la bolsita y las dos bolsas funerarias. En todos los casos se trata del denominado punto corrido envuelto ("whipping stitch"), pero presenta algunas diferencias en su confección entre las prendas mencionadas (Figura 17a). Así, mientras que en la pequeña bolsita decorada se trata de una costura realizada con un color contrastante y muy visible, pero que conforma una puntada sumamente prolija; en las bolsas funerarias se han empleado varios tipos de hilos diferentes, de distintos colores y grosores, con un espaciado irregular entre las puntadas y variaciones en la conformación de la figura de la costura, por lo que las uniones presentan un aspecto poco regular. En las dos piezas gruesas (manta y túnica), en cambio, las costuras se han realizado con hilados similares a los usados como elementos estructurales del tejido, por lo que las uniones laterales quedan disimuladas en las dos prendas. Uno de los fragmentos de tela también presenta una costura de unión entre dos bordes elaborada con punto corrido envuelto, sin embargo, en este caso, creo que la puntada cumple además con un fin decorativo, ya que adopta la configuración de una línea en zigzag, realizada en un color que se destaca sobre el tono claro de la tela lisa (Figura 17b). No he identificado atributos que puedan describirse como costuras de reparación o zurcidos en las telas. Sin embargo, creo que es posible hablar de eventos de arreglo o conservación de las prendas. En la parte superior de una de las mangas del unku, la correspondiente a la mitad más deteriorada de la pieza, y a la altura del hombro, he reconocido signos de reparación. Se trata de un conjunto de cinco medios nudos ("half knot") por medio de los cuales ciertos elementos de trama se anudan a la última urdimbre

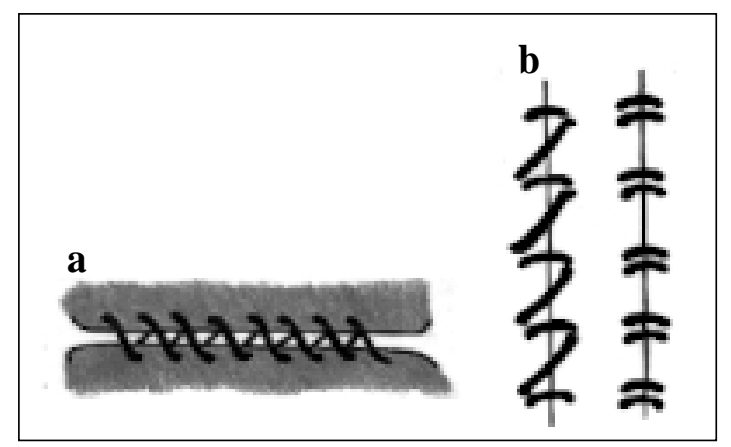

Figura 17 a y b. Costuras de unión. del orillo lateral o, en otros casos, se observa la variante en que dos elementos de trama contiguos se anudan por encima del último elemento de urdimbre (Figura 18).

Las puntadas o costuras que pueden describirse como recursos decorativos han sido identificadas como terminaciones de orillo de urdimbre. En la muestra he podido relevar los siguientes tipos. Una cadeneta aparece en varias prendas en los orillos de urdimbre. La costura ha sido elaborada como un punto de aguja, en que cada puntada toma dos (o en algunos casos tres) elementos de la urdimbre en el doblez correspondiente al encabezamiento (Figura 19a). Tres prendas presentan este tipo de terminación decorativa: el unku, la manta y la chuspa. Tanto el unku como la manta presentan la terminación solamente en uno de los dos orillos de urdimbre, pero en ninguno de los dos casos la costura se ha conservado completamente a lo largo de toda la extensión del borde, por lo que es posible que su ausencia en el orillo opuesto se deba a razones de conservación. La tercera pieza mencionada, la chuspa, sí conserva la cadeneta decorativa en ambos orillos de urdimbre, en lo que constituye el borde superior de la bolsita. Sólo

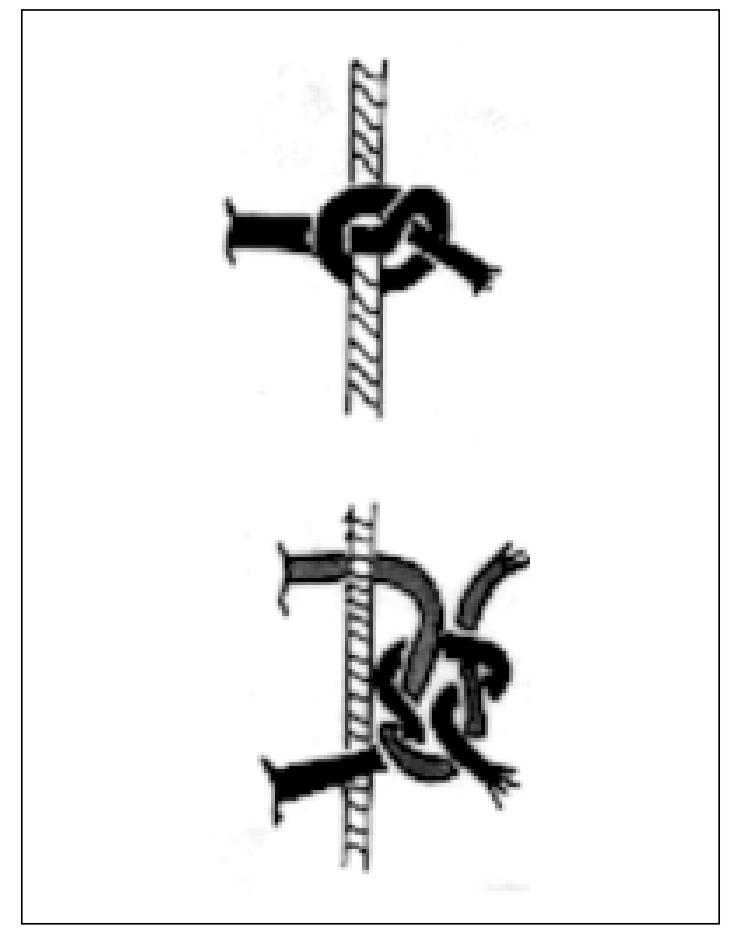

Figura 18. Esquema de los tipos de uniones o "nudos de reparación" en los bordes de trama de la túnica. 
en el caso de la manta la costura produce un efecto decorativo por contraste de color, ya que el hilo de costura presenta un tono mucho más oscuro que el predominante en el resto de la pieza. En los otros dos casos la costura está confeccionada con un hilo de un color muy similar al de los elementos de urdimbre, por lo que su presencia aparece disimulada. Esta situación es más acentuada en el caso de la bolsita donde, además, una serie de eslabones de cierre unidos al borde ocultan la cadeneta prácticamente en la mayor parte de su extensión. Las cadenetas en el borde de urdimbre han sido utilizadas frecuentemente como terminación decorativa, constituyendo un atributo frecuente y "diagnóstico" de los textiles formativos transandinos. Esta cadeneta en el borde de urdimbre constituye un rasgo distintivo de ciertas piezas textiles, fundamentalmente mantas y túnicas, recuperadas en sitios arqueológicos asignados al momento Formativo en el norte de Chile, como por ejemplo Pisagua, Tarapacá-40, Playa Miller7, Topater-1, entre otros (Ulloa 1974, Agüero 1995 y 2000, Cases 2000, Agüero y Cases 2000). Con respecto a otros antecedentes sobre el uso de estas terminaciones decorativas en las prendas textiles, podemos mencionar nuevamente el conjunto de piezas recuperadas en los abrigos rocosos de Las Pirguas (Pampa Grande, Salta). Una de las características presentadas por este conjunto de tejidos "... es el empleo, en gran proporción, del punto cadena en los bordes de las telas" (Rolandi de Perrot y Nardi 1978: 13). Otra costura decorativa en los orillos de urdimbre puede describirse como una puntada de tipo festón (Figura 19b). Son tres los tejidos de la muestra que presentan este tipo de terminación: la pieza rectangular con urdimbres divergentes y peinecillo, uno de los fragmentos elaborado en tapicería y la bolsa funeraria que presentaba la atadura central. En los dos primeros casos, el hilo de la costura es de una tonalidad diferente que la de los hilados visibles en el tejido, acentuando de esta manera el efecto decorativo por contraste de color. En el último caso, el efecto decorativo de la puntada se produce fundamentalmente por textura y no por color, ya que el hilo usado para la costura es idéntico al hilo que forma la estructura visible del tejido, con la diferencia que para la puntada decorativa se ha utilizado el hilo triple.

Un tercer tipo de puntada decorativa en el borde de urdimbre puede describirse como un punto en- lazado simple, que toma dos pares de elementos de la urdimbre en el doblez correspondiente al encabezamiento (Figura 19c). Este tipo de terminación decorativa sólo se ha registrado en uno de los bordes de la pequeña pieza rectangular decorada recién mencionada, que es la prenda que exhibe la mayor variabilidad de elementos decorativos. Los dos orillos de urdimbre se presentan decorados con puntadas decorativas pero, tanto el tipo de hilos utilizados para la costura como la morfología de la puntada son diferentes, hecho que acentúa una decoración que podríamos calificar de "recargada" si tenemos en cuenta las reducidas dimensiones del tejido, lo complejo de su decoración estructural y la variedad de atributos decorativos superestructurales que presenta. Apoya esta observación que el único caso de bordado aparece también en esta tela. Se trata de un bordado en punto cadena cercano a uno de los orillos de urdimbre de la pequeña pieza (Figura 19d).

Entre los elementos agregados destaca el hallazgo de una cuenta circular de valva $(8 \mathrm{~mm}$ de diámetro) unida, por medio de un hilo que actúa como elemento de costura, a la misma pieza a la que me acabo de referir. Esta pieza presenta un par más de hilos que atraviesan la tela, de faz a faz, de manera similar al primero, lo que permite pensar en que esta prenda pudo estar decorada con otras cuentas más, además de la que se ha conservado hasta hoy. No puedo dejar de mencionar que esta pequeña tela rectangular es sumamente llamativa por la cantidad y variedad de elementos decorativos que exhibe, algunos de los cuales representan rasgos únicos y notables en el conjunto

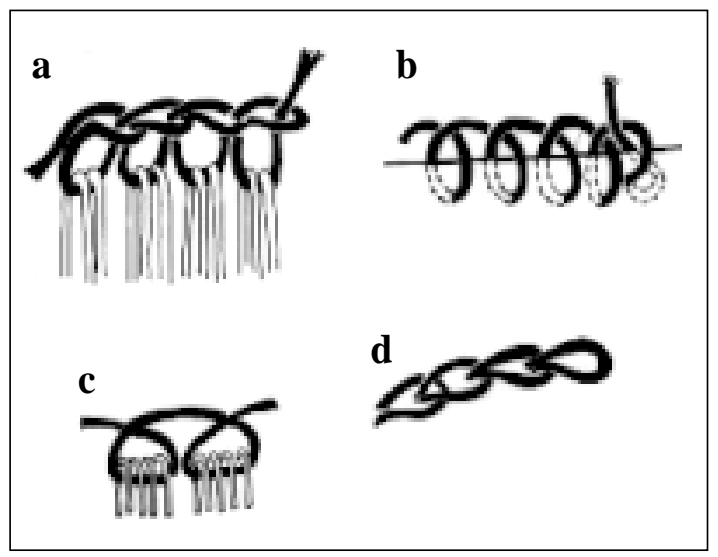

Figura 19. Tipos de puntadas decorativas: a) cadeneta; b) punto festón; c) punto enlazado y d) bordado punto cadena. 
de la muestra, como la cuenta de valva o la presencia de cabello humano como elemento de costura que la une con la bolsa funeraria o pieza mayor. Lamentablemente, no existen suficientes elementos diagnósticos para determinar su posible funcionalidad dentro del conjunto textil funerario.

Sólo uno de los dos fragmentos pertenecientes a la posible faja ha conservado una flecadura superestructural compleja. Enlazados a la costura del borde de trama, se presenta un conjunto de flecos formado por catorce cordeles compuestos, con sus dos extremos unidos al orillo de trama; formando de esta manera un gran fleco de forma semicircular. En la parte central o zona de caída del fleco, los cordeles se han separado en dos grupos de siete, los que están unidos con una costura de tipo "embarrilado" que presenta la variante de un lazo central.

Un elemento superestructural destacable es el que presenta el borde de la chuspa, consistente en una serie de lazos a modo de eslabones que ocupan toda la extensión de los dos orillos de urdimbre. Los eslabones atraviesan la trama a la altura de la primera pasada, que en este caso está representada por la cuerda de telar (Figura 20). Por el centro de los eslabones que conforman esta cadena pasa un cordel que, al ser ajustado, cumplía con la función de cerrar la bolsa y asegurar su contenido. Considero que se trata de un detalle funcional y decorativo sumamente original, sobre el que sólo he relevado un caso similar. Haré referencia al mismo cuando aborde la dimensión iconográfica, al considerarlo por éste, y otros rasgos tecnológicos y decorativos compartidos, una pieza textil relevante para trazar asociaciones con la pequeña bolsa decorada de PP9.

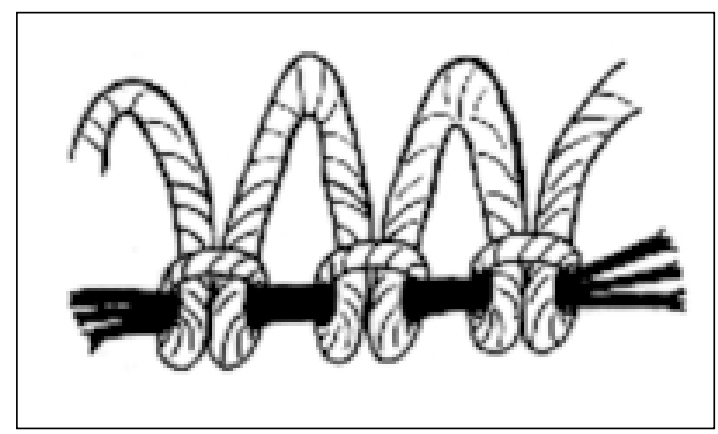

Figura 20. Cadena de eslabones en el borde de la bolsita.
Sobre algunos de los elementos de cordelería asociados a las telas

Entre el material de cordelería recuperado en la tumba se incluyen más de 1.600 fragmentos de hilos, la casi totalidad de los cuales han podido ser relacionados con algunos de los elementos estructurales de las prendas o de los fragmentos de telas. Las principales características de este conjunto de hilados pueden consultarse en un trabajo previo (López Campeny 2001a: 164-205), por lo que quisiera concentrarme aquí en otros elementos de cordelería que presentan ciertos atributos interesantes de destacar.

Ya he mencionado que dos cuerdas unidas entre sí por un nudo central (de 60 y $59 \mathrm{~cm}$ de largo), se recuperaron enrolladas a una de las posibles bolsas funerarias. Se trata de cordeles compuestos (con retorsión) y combinados, ya que para su elaboración se emplearon tanto el cabello humano como la fibra de una palmera (Acrocomia sp.). En forma sintética, ambas cuerdas presentan una porción terminal de fibra vegetal, un tramo intermedio que combina fibra vegetal y cabello y, finalmente, una porción terminal constituida exclusivamente por cabello (Figura 21). Las dos cuerdas son casi idénticas en la longitud de los tres diferentes tramos, pero presentan direcciones de hilado, torsión y retorsión inversas entre sí (z s 3Z - s z 3S). No presentan un diámetro uniforme en toda su extensión, sino que éste se incrementa progresivamente, desde los $4 \mathrm{~mm}$ en el extremo de cabello, hasta alcanzar los $10 \mathrm{~mm}$ de espesor en el extremo de fibra vegetal. Los cuatro extremos de las cuerdas están rotos lo que, sumado a las características del contexto de hallazgo, me llevó a plantear la posibilidad de que ambas piezas presentaran una función diferente, previa a su rotura y a su utilización en el contexto funerario. La característica más reveladora en este sentido fue la observación del engrosamiento paulatino del diámetro de los cordones, lo que permitió relacionarlos con los cordones laterales de

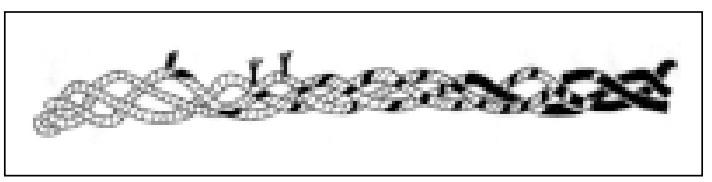

Figura 21. Esquema de la combinación de materias primas en los cordones laterales de la honda. 
una honda (Rolandi de Perrot com. pers. 2000). La parte central o lugar donde descansa el proyectil, no se ha conservado, pero debió ubicarse entre los extremos más gruesos de fibra vegetal, mientras que en uno de los otros dos extremos más delgados, debió hallarse el ojal de la honda. En el interior de una de las piezas cerámicas que formaban parte del ajuar se rescató un elemento de cordelería que corresponde a esta porción de la honda. Se trata de un tramo correspondiente a la porción de cabello, la que forma un lazo y está recubierto con una costura de tipo "embarrilado", combinando hilos de dos colores contrastantes (blanco y café), que alternan en diferentes tramos del ojal (Figura 22). La asociación de estas cuerdas con los cordones de una honda pone en evidencia una reutilización de esta arma, la que se ha transformado en un elemento accesorio de una prenda textil en un contexto funerario. Al respecto, resulta relevante la siguiente observación de Rolandi de Perrot:

“...la honda fue ampliamente usada como arma de guerra o de caza. Al ir transcurriendo el tiempo comenzó paulatinamente a perder su carácter funcional y se transformó en un elemento constituyente del atavío del indígena” (1973: 282-283).

Por otra parte, Agüero (1994: 141) menciona que la honda utilizada actualmente entre los pastores de llamas para guiar a los animales, se lleva comúnmente sujeta alrededor de la cintura o de la cabeza, pero sin perder su función utilitaria como arma arrojadiza. Asimismo identifica la presencia de una honda entre los accesorios decorativos asociados a un turbante en un contexto funerario de la costa norte de Chile y menciona otros ejemplos de hondas elaboradas para ser empleadas exclusivamente con fines ceremoniales o decora-

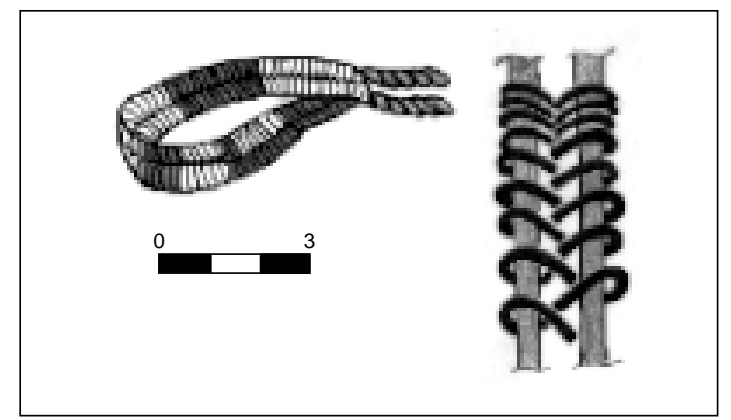

Figura 22. Esquema del lazo que constituye el ojal de la honda y costura tipo "embarrilado". tivos. Estas últimas presentan siempre atributos morfológicos y tecnológicos diferentes a los de las hondas usadas únicamente con fines utilitarios (1994: 139). Otro rasgo destacable de estas cuerdas es el empleo para su confección de fibra de una palmera (Acrocomia sp. Fam. Palmae), es decir, una materia prima no local procedente de las tierras bajas. Su presencia en el registro arqueológico aporta más evidencias a las ya documentadas respecto de una amplia movilidad desarrollada por estos grupos y/o la existencia de redes sociales para el intercambio de productos a gran distancia, las que ponían en contacto a las poblaciones puneñas con asentamientos ubicados a menor altitud.

Otro ejemplar sumamente notable es una cuerda elaborada en fibra de camélido de color marrón muy oscuro, de $11 \mathrm{~mm}$ de diámetro y un poco más de $5 \mathrm{~m}$ de longitud. Posee un total de ocho cabos torsionados de a pares con la siguiente fórmula: s z 4S. Presenta tres medios nudos en distintos sectores de su tramo y un cuarto nudo que forma un lazo complejo cercano a uno de los extremos (Figura 23). En general, presenta buen estado de conservación y parece haber preservado su longitud original, sólo muestra algunos faltantes entre los cordeles en ciertos tramos en los que se presenta visiblemente adelgazada. En

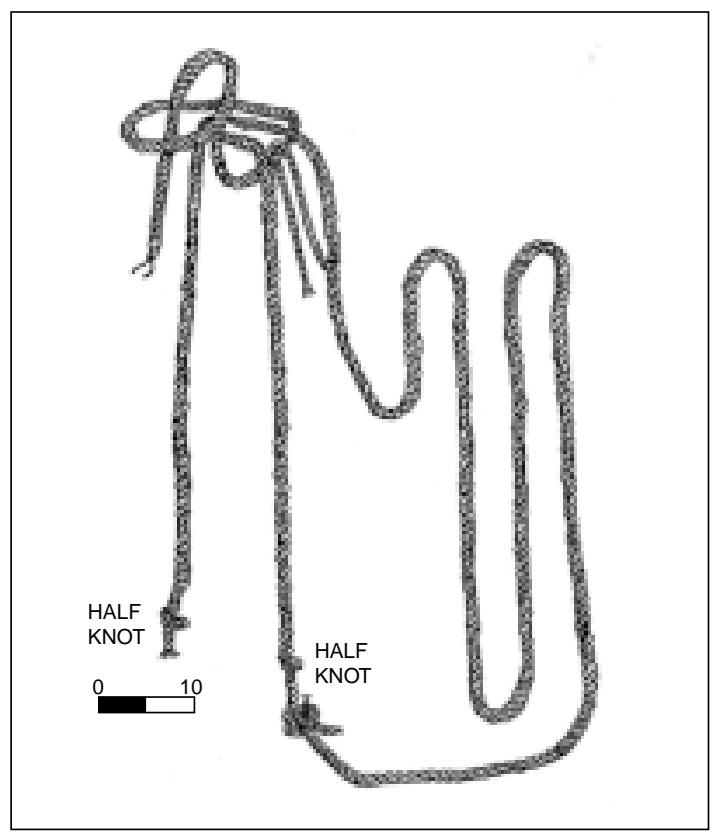

Figura 23. Esquema de cuerda con nudos. 
uno de los extremos puede aun observarse el inicio de la cuerda, que aun conserva un cordel (moliné z S) que se utilizó para atar a algún punto fijo e iniciar la torsión. Estaba dispuesta en forma enrollada y asociada a ella se encontró un cordel grueso de fibra vegetal que cumplía con la función de sujeción, al asegurar la cuerda con un movimiento de giro a su alrededor. Además de su amplia longitud y su importante grosor, otros detalles técnicos de la cuerda son llamativos. En primer lugar la presencia de los nudos, sobre todo el que forma un lazo en uno de los extremos de la cuerda. Más llamativo aún es que de uno de los tramos de cuerda que se desprende de este lazo se separa uno de los cuatro cordeles que conforman la cuerda, invierte su dirección y se introduce en el interior de la estructura que conforma el lazo. En otra porción, sólo en un corto tramo, uno de los cuatro cordeles que conforman el cordón principal presenta un hilado moliné. Sin embargo, ninguno de sus atributos tecnológicos es determinante para inferir alguna funcionalidad asociada a esta larga cuerda. El hecho de que el contexto funerario haya sido reabierto y la posibilidad de que los materiales fueran reorganizados durante este evento complica un poco más el plano de las inferencias, ya que no es posible saber si la cuerda desempeñaba alguna función específica (p.e., amarre del fardo) y/o se ubicaba en una posición diferente, cuando el cuerpo estaba enterrado, a la que se recuperó durante la excavación. Aun corriendo todos estos riesgos, me animo a plantear dos posibles interpretaciones sobre la presencia de este artefacto en el contexto funerario. La primera se vincula con la forma en que la cuerda fue encontrada. Estaba arreglada de tal manera que, antes de que procediera a su limpieza y desenrollado, recordaba la estructura de los adornos cefálicos registrados en los "enturbantados", en cementerios formativos del norte de Chile, como en Arica (Agüero 1994 y 1995, Gallardo 1993). Si bien hasta el momento no se ha recuperado evidencia directa del uso de este tipo de adornos para el Período Formativo en Antofagasta de la Sierra, ${ }^{15}$ sí se ha planteado la utilización de

\footnotetext{
15 Se ha registrado el uso de "cintas planas" — cordeles unidos mediante costuras transversales - como adornos cefálicos en contextos funerarios de Loro Huasi, Prov. de Catamarca, junto con una docena de cordeles teñidos por amarre. Todos estos cordeles se encontraban enrollados en la cabeza de una de las momias y han sido asociados a un contexto más tardío que el aquí considerado (Renard 1997: 299).
}

turbantes o envoltorios cefálicos a partir del análisis de representaciones rupestres atribuidas a este período (Martel 2000: 34-35). La segunda alternativa que planteo se relaciona con la posible función simbólica de esta cuerda, en relación con ciertas prácticas vinculadas al ritual funerario. Por lo tanto, analizaré este aspecto cuando trate esta última dimensión de aproximación a los textiles.

\section{La dimensión expresiva. Análisis de la iconografía textil y estudio comparativo de diseños relevados en otras materialidades}

Sobre el uso del color, diseños decorativos y principios de simetría

El análisis de esta segunda dimensión de las piezas textiles involucró, en primer término, un estudio del empleo del color y de la iconografía como principales atributos decorativos de las prendas. La denominación del color en las piezas fue según "The Munsell Color Chart for Plant Tissues", y para el registro de los tonos próximos al blanco y al negro, se utilizó como complemento "The Munsell Chart for Soils". Cuando la pieza presentaba algún tipo de diseño decorativo, este fue descrito en forma completa, lo que representó: identificar la técnica empleada para su conformación, indicar la ubicación de los diseños, describir la distribución de las figuras en el diseño y detallar la disposición de los colores en las figuras y el fondo. El análisis del uso del color en las prendas textiles no fue un dato relevado con el único afán de describir la decoración de las telas. Como han evidenciado algunos estudios, la organización de los colores en el mundo andino remite a todo un sistema de creencias; y la composición de los diseños y la forma de organizar los tonos están en relación con un sistema cultural más amplio de significados (Cereceda 1990). La primera etapa para adentrarse en este mundo de significados es la comprensión de la forma de organizar y de emplear los colores, lo que sólo se logrará partiendo de la observación y la descripción detallada de los atributos decorativos en las prendas.

En nuestro caso, todos los tejidos utilizan la fibra de camélido en sus tonos naturales. Como ya mencioné previamente, el color se ha utilizado como elemento decorativo para crear listados en faz de urdimbre y diseños con figuras geométricas de mayor complejidad. En la mayor parte de los 
casos se ha buscado crear un efecto decorativo por contraste, al poner en contacto colores claros con oscuros y logrando, frecuentemente, la configuración de las figuras a través de la técnica del diseño en positivo y negativo.

Con respecto a los diseños registrados en el material analizado, podemos decir que, sin incluir los dos ejemplares que presentan listados, (el unku y la manta), sólo tres piezas (un total de cuatro fragmentos) presentan diseños decorativos más complejos. Se trata de la bolsita o chuspa, los dos fragmentos de tapicería atribuibles a una faja y la pieza rectangular profusamente decorada y cosida con cabello humano a una de las bolsas funerarias. En todos los casos se trata de diseños geométricos abstractos. No he relevado ningún diseño figurativo naturalista o que presente referentes objetivos de la realidad concreta. Existe un dominio de las líneas rectas, tanto con direcciones verticales y horizontales como diagonales. El efecto de los diseños se ha logrado casi siempre por un efecto de contraste entre los colores de las figuras y del fondo, emergiendo figuras oscuras de un fondo siempre claro. Pero este mismo contraste produce el siguiente efecto: si uno observa los tejidos detenidamente, las imágenes se invierten y el fondo y las figuras intercambian sus lugares, permitiendo ver figuras claras desprendiéndose de un fondo oscuro. Este constante juego dual para crear los diseños está presente en varios aspectos, no sólo en la frecuencia con que se han utilizado dos colores contrastantes en juegos de positivos y negativos, sino también en los principios de simetría empleados para la construcción de los diseños: cada motivo está construido a partir de principios de simetría bilateral e imagen espejo, tanto en forma como en colorido. Dos de las tres piezas a las que me refiero -la chuspa y la pieza rectangular- presentan un diseño dominante en la mayor parte de la pieza que es simétrico en relación a otro diseño ubicado en el centro de la pieza, el que actúa como elemento de separación dual entre dos espacios idénticos. Si además incluimos en este análisis a las piezas que presentan como decoración motivos listados, podemos apreciar que existe una serie de similitudes en la simetría de las decoraciones, lo que da unidad al conjunto. En las dos piezas decoradas con franjas verticales la distribución de los colores de las bandas se ordena de acuerdo con un esquema de simetría axial, que responde a principios de simetría especular. En síntesis, tanto la repetición rítmica o alta redundancia de los motivos, como la construcción de los diseños a partir de ejes de simetría bilateral son dos principios que estructuran las representaciones decorativas de este conjunto de textiles.

El plano comparativo. Primera parte:

Los diseños textiles de PP9 y representaciones relevadas en otros soportes iconográficos. La cerámica y el arte rupestre

Como he mencionado, contamos entre los elementos disponibles para contextualizar a las piezas textiles, con un fechado obtenido de semillas de chañar asociadas a la tumba. Este fechado ubicaría al evento funerario en algún momento entre el 400 y el 550 DC datando, de manera indirecta, a las prendas textiles. Sin embargo, me pareció conveniente poder contar con mayor cantidad de indicadores que me permitieran contextualizar a los materiales textiles en forma complementaria a la información proporcionada por el fechado radiocarbónico. Decidí entonces emplear otros referentes iconográficos materiales, diferentes al textil, que presentaran diseños comparables con la iconografía relevada en las telas y que contaran además con mayores referencias cronológicas y/o asociaciones contextuales. Esto no es un planteamiento novedoso en sí mismo, ya que otros autores han propuesto el uso de indicadores estilísticos como una metodología válida para establecer asociaciones entre representaciones de arte rupestre y diseños plasmados en diferentes soportes materiales artefactuales (Aschero 1988, Olivera y Podestá 1993, Sinclaire 1997, Gordillo et al. 2000). Aunque pueden existir una serie de riesgos en la utilización de la analogía estilística para trazar relaciones cronológicas y/o culturales, fundamentalmente en lo que respecta a las notables diferencias que pueden existir entre los variados contextos de producción y de uso de las tecnofacturas comparadas, cabe mencionar las relaciones de semejanza formal que he podido detectar entre algunos de los diseños decorativos presentes en las piezas textiles de PP9 y ciertas representaciones relevadas en dos diferentes soportes iconográficos como la cerámica y el arte rupestre.

Algunos investigadores ya han identificado similitudes formales entre ciertas representaciones rupestres de sitios formativos de Antofagasta de la Sierra y diseños relevados en cerámica proce- 
dente de la zona valliserrana del N.O.A. (Podestá 1989, Olivera y Podestá 1993, Podestá y Manzi 1995). De esta manera, como las representaciones formales del arte rupestre de la puna han sido analizadas comparativamente con las decoraciones cerámicas valliserranas, en este estudio intenté vincular las representaciones de ambos soportes con los elementos decorativos presentes en algunas de las piezas textiles aquí presentadas. Con este aporte sólo estoy extendiendo el análisis comparativo previo, incorporando nuevas variables de referencia en lo que se transforma, de esta manera, en un análisis contextual mucho más amplio.

Consideraré aquí los diseños presentes en dos de las piezas textiles. El primero es el motivo de escalonados rectos superpuestos o escalonado piramidal, representado en forma continua en toda la extensión de la bolsita o chuspa. El segundo diseño es el de peinecillos, que constituye la decoración central de la pieza rectangular cosida a una de las bolsas funerarias. El primero de estos motivos ha podido ser relevado tanto en el arte rupestre de Antofagasta de la Sierra como en cerámicas asignadas a entidades culturales valliserranas de momentos formativos. Con respecto a este último material, es importante mencionar que este tipo de cerámicas también han sido identificadas en sitios agropastoriles del fondo de cuenca de Antofagasta de la Sierra (Olivera 1992) $\mathrm{y}$ en forma abundante en la superficie del sitio PP9, en el curso medio del río Las Pitas.

En el arte rupestre de Antofagasta de la Sierra se ha relevado en forma recurrente un diseño designado como "motivo de rectángulo con diseño geométrico en su interior" (Podestá et al. 1991: 41). Estas representaciones rupestres han sido relacionadas con la fase geométrica de la manifestación estilística Ciénaga, caracterizada por el énfasis en el uso de diseños lineales, abstractos y geométricos los que, frecuentemente, se distribuyen en forma de frisos o paneles (Podestá et al. 1991: 41). En el interior de estos rectángulos se inscriben diferentes figuras geométricas, entre las que me interesa destacar un diseño geométrico consistente en una figura escalonada, grabada en surco fino, tal vez inciso en "V" o en "U", encolumnado en repeticiones rítmicas (Aschero y Martel com. pers. 2000). Este tipo de representación es similar al motivo de escalonados superpuestos descrito para la chuspa y ha sido identificado en un bloque de ignimbritas del sitio El Sembrado, ubicado en el curso medio-superior del río Las Pitas, cercano a PP9 (Figura 24).

Los datos de la cerámica son más numerosos y presentan una serie de características en común, lo que otorga mayor consistencia a la comparación entre las representaciones plasmadas en los dos soportes. Es que el diseño de escalonado piramidal ha sido registrado entre los diseños empleados en la etapa geométrica de lo que se conoce en el N.O.A. como estilística Ciénaga, y piezas cerámicas que exhiben este diseño grabado han sido relevadas en la colección de Instituto de Arqueología y Museo (I.A.M.) de la Universidad Nacional de Tucumán (López Campeny 2001a). Este grupo de piezas cerámicas comparte una serie de características formales y contex-

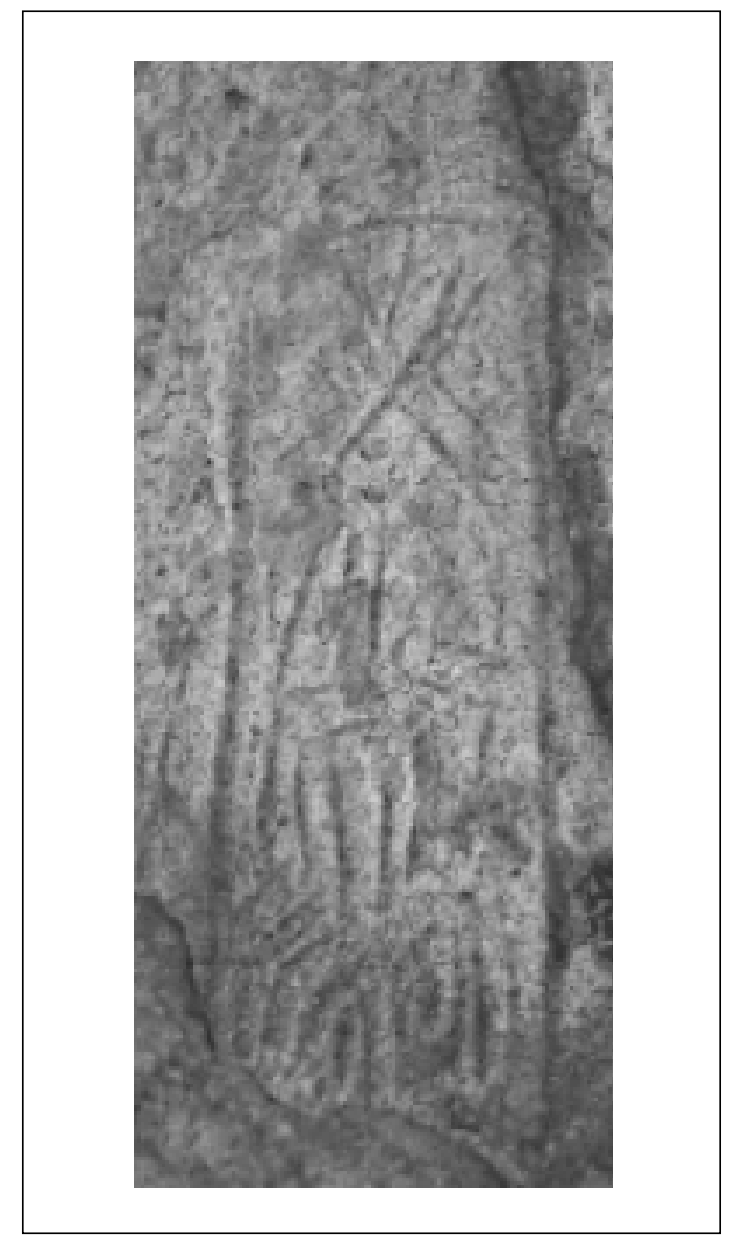

Figura 24. Grabado rupestre. Sitio El Sembrado (Antofagasta de la Sierra). Rectángulo con diseño interior que incluye la figura del escalonado piramidal. 
tuales. Los grabados se han realizado en todos los casos en piezas que se han descrito comúnmente como "jarros", de forma subglobular, cuello apenas insinuado y que presentan un asa plana ubicada en sentido vertical. Todos los ejemplares corresponden a lo que estilísticamente se conoce con el nombre de Ciénaga gris inciso y, en los casos que poseen registro de su hallazgo, todas las piezas han sido recuperadas en contextos funerarios del Depto. Belén (Prov. de Catamarca). Las similitudes formales entre la decoración de estas cerámicas y el diseño presente en la chuspa no se limita a la presencia de la figura escalonada como unidad básica del diseño, sino también a que el mecanismo para construir la decoración consiste, en ambos soportes, en la inversión alternada de esta figura básica, en un movimiento continuo de ascenso y descenso de las líneas. Además, el diseño no se distribuye en campos o sectores definidos, ni se limita a ciertas porciones de la pieza sino que ocupa, tanto en el textil como en las vasijas, toda la superficie del artefacto. También existen elementos que otorgan variabilidad a la forma de representación del escalerado en las piezas cerámicas, debido a que mientras algunas presentan una figura representada por un único trazo delgado, como es también el caso de la bolsita, otras cerámicas exhiben la figura del escalonado formada por líneas que encierran campos divididos entre sí por un efecto de contraste positivo-negativo, logrado por el grabado de un campo, mientras que el sucesivo permanece liso o sólo pulido (Figura 25).
El segundo diseño que fue posible analizar comparativamente en una pieza textil y en ejemplares cerámicos, es el obtenido en el telar con la utilización de la técnica estructural de peinecillos. El pequeño textil rectangular, profusamente decorado, lo exhibe como diseño central, pero también he podido identificar diseños formalmente comparables en piezas cerámicas pertenecientes a la colección del I.A.M. También se trata en este caso de jarros correspondientes al estilo Ciénaga gris inciso y el contexto de recuperación, así como la procedencia geográfica, coinciden con lo reseñado para las cerámicas antes analizadas. En estas vasijas he registrado representaciones de paneles grabados con un diseño que se ha conocido con el nombre de "damero". La configuración final de esta decoración es resultado de un efecto de contraste positivo-negativo, creado por el grabado en el interior de pequeñas superficies rectangulares que alternan, en sentido vertical y horizontal, con otras superficies de igual forma y tamaño que exhiben la cara pulida de la pieza. Esta decoración en "damero" en las piezas cerámicas es formalmente idéntica a la técnica decorativa estructural que en las piezas tejidas a telar recibe el nombre de peinecillos. Todas las piezas cerámicas que exhiben este diseño presentan un asa ubicada en sentido vertical en uno de los costados de la pieza. Aunque en la mayoría de los casos el asa es plana o en forma de cinta, me resultó muy sugerente que, en otros casos, el asa exhibe claramente la forma de un cordel (Figura 26). Esto es un elemento importante como fundamen-

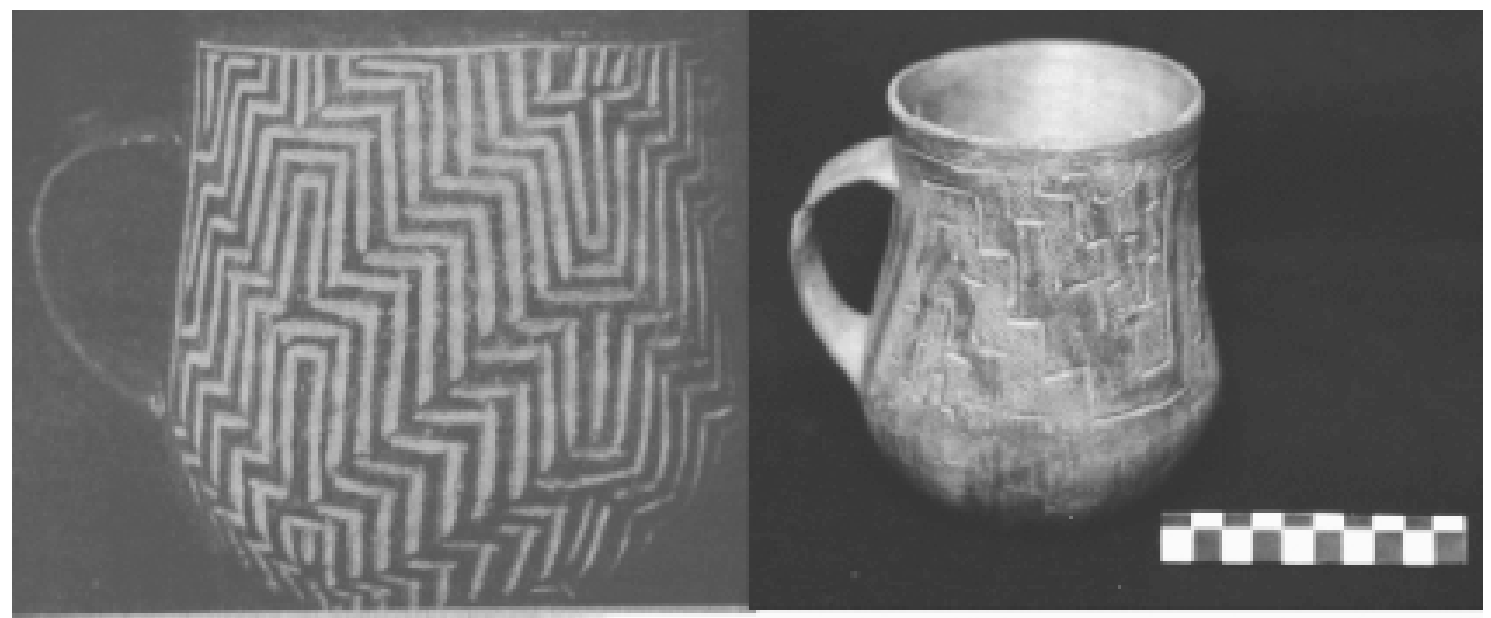

Figura 25. Cerámicas con motivos de escalonados superpuestos. Izq.: Tomado de González y Pérez (2000: 52). Der.: Pieza № 5447. Colección I.A.M. (Tucumán). 


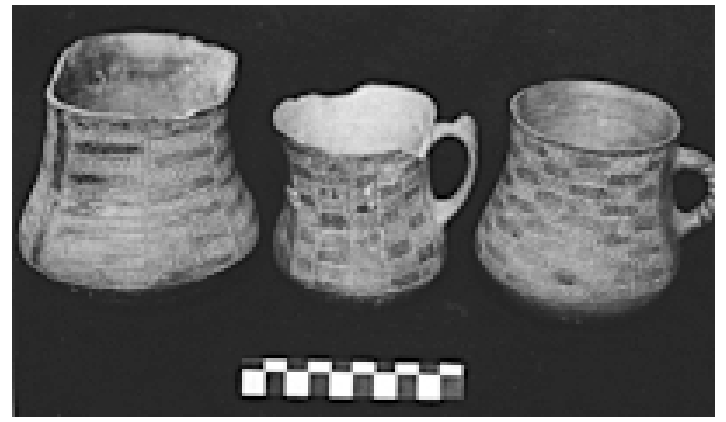

Figura 26. Cerámicas con diseño de dameros o "peinecillos". Notar el asa en forma de cordel en la pieza de la derecha. Piezas No 2435, No 0903 y º1506. Colección I.A.M. (Tucumán).

to para la comparación que planteo entre las decoraciones de ambos soportes, ya que nos muestra una relación entre la representación de ciertos elementos textiles (hilos torsionados) y su empleo para la decoración de las piezas cerámicas.

El plano comparativo. Segunda parte: relaciones entre la chuspa de PP9 y una chuspa recuperada en un contexto funerario de San Pedro de Atacama

También he identificado una serie de semejanzas, tanto técnico-estructurales como estilísticas, entre la chuspa recuperada en el contexto funerario de PP9 y una bolsita perteneciente a un fardo funerario procedente del cementerio de Quitor, en San Pedro de Atacama. El fardo del que procede esta bolsita ha sido conocido en la literatura arqueológica a partir de dos trabajos de investigación. En el primero, Llagostera (1995) vincula ciertos componentes artefactuales foráneos, recuperados en San Pedro de Atacama, con la manifestación cultural Aguada, del N.O.A. Entre estos materiales ajenos a la tradición de San Pedro el autor menciona una pieza textil de características notables. Se trata de una túnica decorada por la técnica de teñido por amarra y reserva (plangi), cuyos diseños iconográficos (una figura serpentiforme escalonada bicéfala y la representación de un felino sentado de perfil) le permiten postular a dicha prenda "como de filiación Aguada" (Llagostera 1995: 20). Esta túnica formaba parte del mismo fardo funerario del que procede la bolsita que aquí me interesa considerar. El segundo trabajo que analiza el citado fardo es el de Conklin y Conklin (1996-97), quienes llevan a cabo el proceso de desmontaje de la momia y posterior análisis de las piezas textiles que conformaban las envolturas. Estos autores también resaltan el origen foráneo de la túnica teñida por amarra, pero agregan que dos piezas más de este fardo serían ajenas a la tradición de San Pedro de Atacama por presentar técnicas inusuales para los contextos conocidos de este lugar, siendo su lugar de origen más probable el N.O.A. Las dos piezas restantes son una faja decorada con la técnica de tapiz entrelazado y una pequeña bolsita en faz de urdimbre que presenta diseños geométricos (Figura 27). Es sobre esta última pieza que quiero centrar la atención. Además de la descripción técnica realizada por Conklin y Conklin (1996-97), he podido observar personalmente la pieza, conjuntamente con especialistas textiles ${ }^{16}$, por lo que cuento con un importante conjunto de elementos para plantear una serie de semejanzas entre esta chuspa y la recuperada en Antofagasta de la Sierra. Ambas piezas presentan la misma estructura y técnica textil, ya que han sido elaboradas empleando una técnica recíproca con dos elementos, lo que puede observarse en la configuración del

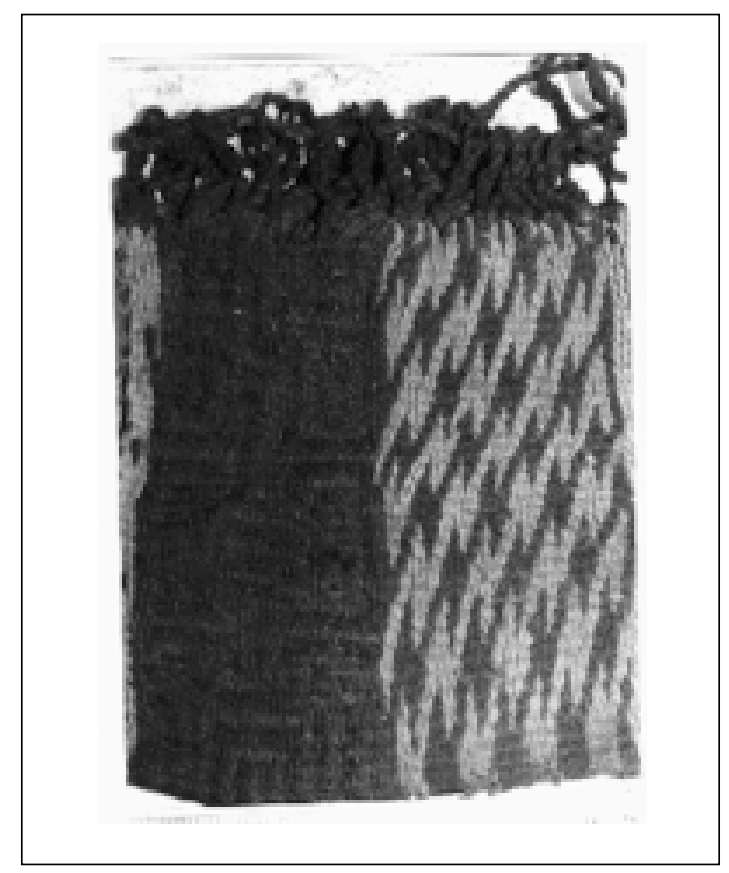

Figura 27. Chuspa de San Pedro de Atacama, Cementerio de Quitor. Foto: Susana Renard.

16 En el marco de la XV Reunión Anual del Comité Nacional de Conservación Textil, llevada a cabo en el Museo Arqueológico R. P. Gustavo Le Paige s. j. en San Pedro de Atacama, durante noviembre de 2001 
patrón de los diseños, presentando -las dos bolsas- un motivo central con respecto al cual es simétrico otro diseño que se repite en ambas caras de las bolsas, hacia arriba y hacia abajo en relación con este motivo central. En ambas piezas las urdimbres han sido torsionadas en forma simple, es decir que un solo par de urdimbres torsionan entre sí, lo que queda atestiguado por la no inversión de los colores entre una y otra faz en el sentido vertical y por la orientación inversa de las inclinaciones de las urdimbres en cada uno de los extremos, en ambas piezas. En el ejemplar de San Pedro de Atacama las urdimbres además han sido transpuestas para crear un diseño bicolor de líneas en zigzag. La forma y dimensiones de ambas piezas son similares, también coinciden en su función general (como contenedor), comparten una misma estructura o conformación de la decoración (simetría sobre el fondo del doblez) y ambas piezas han sido recuperadas en contextos funerarios. Pero además, Conklin y Conklin mencionan que

"...la bolsa tiene una serie de lazos atados alrededor del borde superior con un cordel entrelazado para cerrarla" (1996-97: 191).

Como he destacado, la bolsita de PP9 también presenta un original sistema de cierre consistente en una cadeneta en el borde, a través de cuyos eslabones pasa un cordel para asegurar la abertura. Todo este conjunto de semejanzas técnicas y decorativas entre las bolsas permite proponer una tradición textil común para ambas piezas, pero ¿cuál sería el lugar de su procedencia? Expondré en primer lugar los motivos por los cuales considero que las piezas no proceden de San Pedro de Atacama, lugar donde se recuperó uno de los dos ejemplares.

Los datos que se conocen en relación con la tecnología textil formativa del Norte Grande de Chile procede de los numerosos cementerios que se han excavado, así como de las extensas colecciones textiles que han sido analizadas por diferentes investigadores. Me interesa aquí resaltar las características principales que presenta un tipo especial de textil, las bolsas de menor tamaño o chuspas. Estas piezas constituyen uno de los hallazgos más representativos en los sitios formativos del norte de Chile, por lo que la muestra a partir de la cual se desprenden sus características de elaboración es importante en términos cuantitativos. A partir de los trabajos de investigación se conoce que la forma de elaboración más común y recurrente de estas bolsas, durante el Formativo, fue la técnica de enlace simple, malla o anillado, ya sea en fibra vegetal o de camélido (Agüero y Cases 2000, Cases 2000, Horta 2000 Ms). Es decir, que las bolsas se confeccionaban empleando una técnica de un solo elemento, donde un hilo se enlaza sobre sí mismo, con la ayuda de una aguja, para producir diferentes tipos de mallas enlazadas, con o sin nudos. El registro arqueológico textil muestra que las bolsas tejidas a telar fueron muy escasas y los pocos ejemplares confeccionados en faz de urdimbre que se recuperaron no presentan ningún tipo de decoración, a lo sumo, muestran listados en el sentido de las urdimbres (Agüero y Cases 2000). Para San Pedro de Atacama, Agüero y Cases (2000) sólo han identificado una bolsa que puede adscribirse, por sus características técnicas, al Formativo, y se trata de un ejemplar rectangular de base curva tejida en anillado. A esto puedo agregar que, entre el resto de los materiales textiles recuperados durante el desarmado del fardo ${ }^{\circ}$ 1983:15 de Quitor2 (Conklin y Conklin 1996/97) y asociadas a la chuspa decorada con los lazos en el borde, se cuentan otras cinco bolsas tejidas. Una de ellas ha sido confeccionada con técnica de malla y las cuatro restantes corresponden a tejidos elaborados en telar. Sin embargo, tres de estas cuatro bolsas corresponden en realidad a pequeños fragmentos de prendas más antiguas y muy deterioradas que han sido reutilizadas, mediante ataduras con cuerdas, para formar pequeñas bolsas. Es decir, sólo una de las bolsas ha sido construida en un telar concebida como tal desde su origen, y corresponde a un ejemplar elaborado en faz de urdimbre y decorado con listados, a lo que sumo que sus dimensiones no son similares a las de las dos bolsitas aquí comparadas, sino mucho mayores (30 x 36 cm; Conklin y Conklin 1996/97). En síntesis, tanto entre los materiales recuperados en el fardo de Quitor, como dentro de la muestra mucho más amplia de textiles relevada para el Formativo del norte chileno, la bolsita decorada con urdimbres torsionadas y transpuestas representa un ejemplar de características únicas sólo comparable técnicamente, hasta el momento, con la pieza recuperada en el contexto funerario de PP9.

¿Cuál es la cronología absoluta que disponemos para cada contexto? Para el fardo de San Pedro, Conklin y Conklin (1996/97: 201) mencionan un fechado de $1290 \pm 50$ años AP. Las semillas aso- 
ciadas a la tumba de PP9 proporcionaron un fechado que es aproximadamente 200 años más temprano, pero creo que existen algunos elementos a considerar previo a efectuar cualquier relación entre los dos fechados. En primer lugar, no se especifica qué material fue fechado en el fardo funerario de Quitor por lo que, en ambos casos, sólo es posible inferir la cronología de las bolsitas en forma indirecta, a partir de las edades de otros materiales asociados contextualmente a las prendas. En el caso de la tumba de PP9, la evidencia muestra que se trata de un contexto perturbado en momentos arqueológicos, sin que sea posible precisar si durante la reapertura se agregaron o se retiraron elementos del ajuar (López Campeny 2001a y 2001b). Por otra parte, también debemos pensar en la posibilidad de que prendas textiles tan complejas, desde el punto de vista estructural y decorativo, pudieran ser conservadas durante mucho tiempo, pasando de generación en generación. Todas estas circunstancias me llevaron a considerar que también en este caso podía ser útil emplear las decoraciones plasmadas en otras materialidades, en un intento por contextualizar, con mayores elementos, la pieza de San Pedro de Atacama.

La bolsita en cuestión presenta una decoración organizada en forma dual en el sentido longitudinal (dirección de las urdimbres). Una de las mitades presenta figuras de rectángulos concéntricos, conectados entre sí de a pares, de color marrón oscuro sobre un fondo rojo. La otra mitad exhibe líneas zigzag en diagonal, que alternan en rojo y amarillo (Figura 28). Nuevamente recurrí a la colección del I.A.M. -con el sesgo que esto puede representar en términos de muestreo- en la búsqueda de relaciones formales entre los elementos decorativos del textil y las representaciones grabadas en piezas cerámicas. Los resultados de esta exploración fueron más que interesantes, ya que pude identificar un conjunto de piezas que presentaban fuertes similitudes estilísticas con la decoración de la chuspa. Estos vínculos no se limitan sólo a la presencia de alguna de las dos figuras básicas (rectángulo concéntrico y línea zigzag en diagonal), sino a la combinación de ambos diseños, reproduciendo la cerámica la estructura dual exhibida por el textil. En algunos casos esta composición bipartita se ha construido empleando el anverso y el reverso de la pieza para representar cada diseño (Figura 29), y en otros ejemplares la conjunción se ha logrado a través del

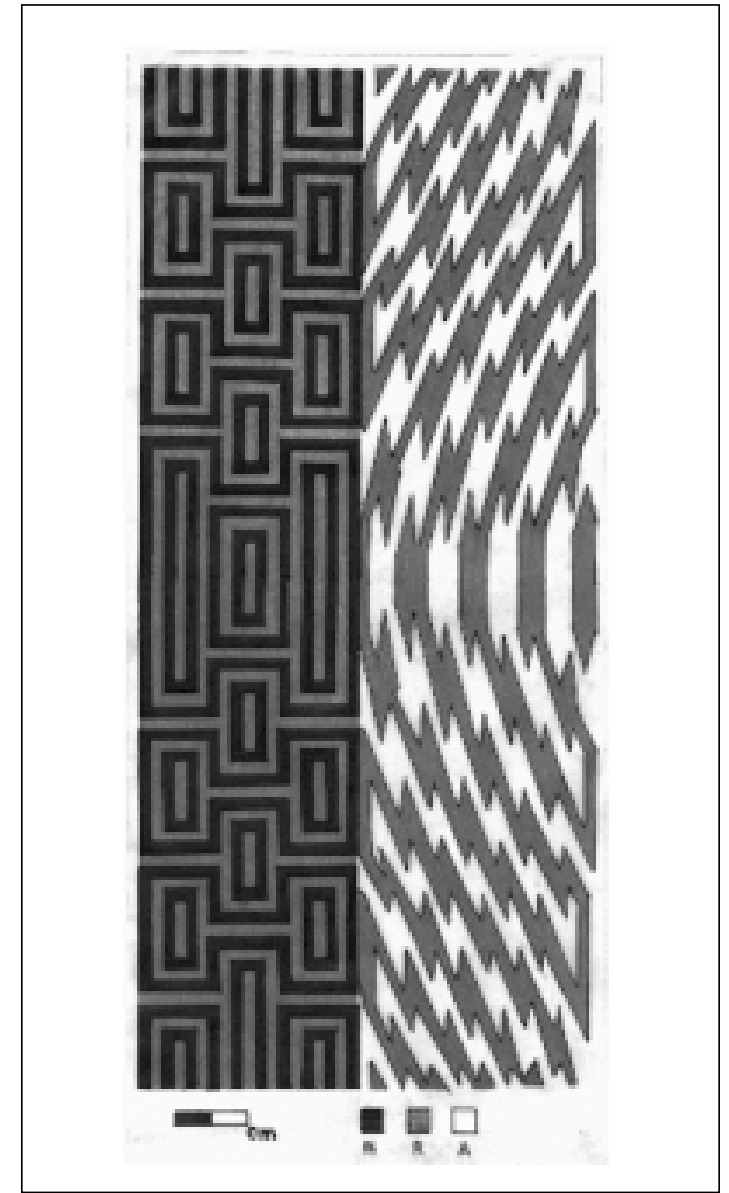

Figura 28. Esquema de los diseños de la chuspa. Presenta decoración dual de líneas en zigzag y rectángulos concéntricos.

grabado de dos paneles donde cada figura ocupa, respectivamente, la mitad superior e inferior de toda la superficie de la pieza (Figura 30).

¿Qué características formales y contextuales presenta este conjunto de cerámicas relacionadas estilísticamente con el textil recuperado en San Pedro? La respuesta es que la morfología general de las piezas, su procedencia geográfica, el contexto de recuperación y su designación en términos de estilo cerámico, coinciden con los de las cerámicas que hemos vinculado con la bolsita recuperada en PP9. Es decir, que se trata de jarros subglobulares, con un asa vertical y decoración grabada, que pueden ser vinculados con el estilo Ciénaga gris inciso y proceden de contextos funerarios recuperados en la provincia de Catamarca.

Estas coincidencias aportarían mayores elementos para reforzar mi propuesta de que ambas bolsi- 


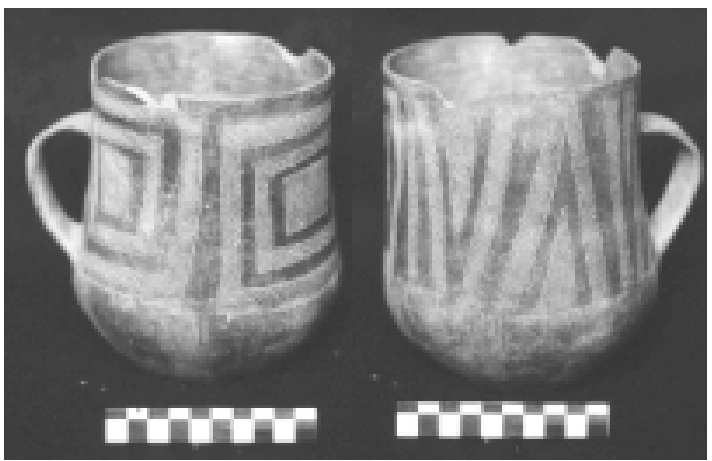

Figura 29. Anverso y reverso de la pieza $\mathrm{N}^{\circ}$ 1879. Colección I.A.M. (Tucumán). Combina los dos diseños principales exhibidos por la chuspa recuperada en San Pedro de Atacama.

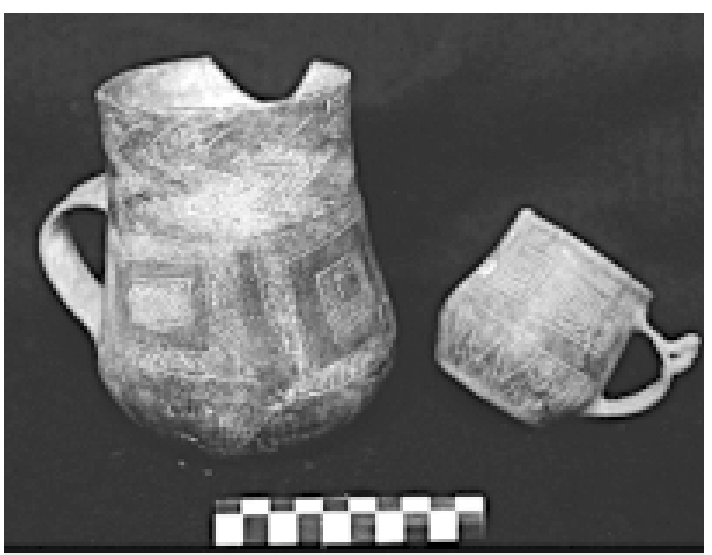

Figura 30. Piezas № 2512 y S/Nº . Colección I.A.M. (Tucumán). Las piezas presentan en forma de paneles (superior-inferior) los dos motivos decorativos principales de la bolsa de San Pedro de Atacama.

tas estarían fuertemente vinculadas entre sí. Ahora estoy en condiciones de responder la pregunta inicial respecto al lugar de procedencia de estas prendas textiles. Luego de considerar las características técnicas más frecuentes empleadas para la construcción de las bolsas durante el Período Formativo en el norte de Chile, de identificar importantes semejanzas técnico estructurales entre la bolsa de PP9 y la de San Pedro de Atacama y reconocer, a su vez, una serie de vínculos estilísticos entre la decoración de ambas bolsas y representaciones plasmadas en el arte rupestre de Antofagasta de la Sierra y en piezas cerámicas del área valliserrana catamarqueña (Valle de Abaucán y Hualfín), puedo decir que todos estos elementos apuntan a un origen en el N.O.A. para ambas piezas textiles, y a su vinculación con el denominado estilo Ciénaga. Esta última interpre- tación me obliga a dejar planteado otro aspecto, que creo tiene el valor de motivar nuevas preguntas para nuestras investigaciones. Se relaciona con la cronología asociada al contexto de recuperación del textil de Quitor (ca. 570 a 770 DC) y a su vinculación con un estilo cerámico que, hasta el momento, se ha considerado en relación con una extensión temporal más temprana y como un antecedente de lo que se denomina estilo Aguada. Dos elementos que se desprenden del análisis de los materiales del fardo funerario de San Pedro de Atacama cuestionarían el estado actual de algunas de las interpretaciones en relación con estos dos estilos cerámicos del N.O.A. El primero de ellos plantea — como resultado del análisis estilístico de la bolsa- la posibilidad de reconsiderar el lapso temporal durante el cual las poblaciones del N.O.A. se manifestaron a través de un estilo decorativo que ha sido designado bajo el nombre de Ciénaga, cuya duración podría haber sido más extensa que la que hasta el momento es aceptada por el consenso general de los investigadores (en torno al siglo VI). El segundo elemento, en íntima relación con el primero, cuestionaría la aseveración de que la fase geométrica y no figurativa de Ciénaga no coexistió, después del siglo $\mathrm{V}$, con el estilo figurativo que caracteriza a Aguada, y de que el primer estilo es el origen, luego de una serie de transformaciones hacia una representación de tipo figurativa, del segundo estilo. En el fardo de Quitor dos piezas textiles adscribibles cada una de ellas a estos dos momentos estilísticos, se han recuperado indudablemente asociadas: la pequeña chuspa decorada y la túnica teñida empleando la técnica de plangi. Como dije, es mi intención solamente dejar planteadas estas dos inquietudes, en la convicción de que necesitamos de más datos para abordar, con mayores elementos de contrastación, estos aspectos de la arqueología del N.O.A.

\section{La dimensión ritual. Algunos aspectos del tejido vinculados con el universo mágico religioso y el ritual funerario}

Los textiles han desempeñado en el mundo andino una amplia variedad de funciones, integrándose de muy diferentes formas en los múltiples aspectos relacionados con la vida cotidiana de las comunidades, lo que incluyó su participación en aspectos vinculados con la muerte y la esfera de las prácticas rituales. La ropa y demás accesorios textiles no sólo sirvieron para vestir y abrigar a 
las poblaciones, sino que también constituyeron símbolos para representar identidades étnicas, atributos para resaltar individuos o grupos remarcando visualmente las diferencias de estatus o de roles, fueron elementos que participaban activamente de circuitos de intercambio social y económico a gran distancia, se emplearon como objetos de poder vinculados con el control político y participaron de numerosos aspectos de la vida ritual, desde el nacimiento hasta la muerte de los individuos. Es sobre esta última dimensión de participación de los textiles que quiero discutir algunos aspectos, valiéndome como pretexto de algunas de las características presentadas por los materiales recuperados en el contexto funerario de PP9.

El primer aspecto, es que todas las prendas textiles analizadas aquí estuvieron representando algún papel en el ritual vinculado con la muerte, por el solo hecho de constituir elementos recuperados en un contexto funerario. Esto implica que, como cualquier otro artefacto, su función no es inherente ni propia al objeto, sino que se ve modificada o complementada por las características particulares del contexto de uso. De esta manera, y partiendo del reconocimiento de las particulares características de estos materiales textiles como elementos de un ajuar mortuorio, la presencia de ciertos atributos en las prendas cobra un sentido diferente, permitiéndonos abordar la dimensión ritual de su participación en un evento funerario.

El poder mágico de los giros:

la torsión inversa o hilado llok'e

Antes señalé la relación existente, entre la dirección de torsión más común en que se realizan los hilados, y ciertas regiones de América, mencionando que la dirección de torsión más extendida en el área andina meridional ha sido la torsión derecha (zS). Esta tendencia también ha sido verificada en los hilos que conforman la estructura de los textiles de PP9, por lo que había retenido la atención en el hallazgo de un hilo moliné de colores contrastantes, hilado en $\mathrm{S}$ y torsionado en $Z$, anudado en el borde inferior de la manta. Para explicar la presencia de este hilado visible en un tejido, con características particulares — su dirección de torsión inversa y su confección con fibra de dos colores- es necesario recurrir a un aspecto relacionado con la confección de los hilados que trasciende a los requerimientos meramente tecnológicos.
La torsión inversa o hacia la izquierda de los hilados recibe en quechua el nombre de $l l o k^{\prime} e^{17}$ y tiene actualmente un sentido vinculado con el universo mágico y ritual, de tal manera que en algunas comunidades aymara el yatiri es la única persona que puede hilar llok'e (Gisbert et al. 1987: 49).

También existen referencias a que en tiempos del Estado Inca el hilado zurdo estaba asociado con ciertos poderes mágicos o sobrenaturales, como lo pone de manifiesto Guamán Poma:

“...otros hechezeros toman un hilo torcido a lo izquierdo con blanco y negro y ponen en los caminos y lo ponen como lazos de los demonios por donde an de pasar sus enemigos para que le coxa el lazo y hechisos puesto en ellos hecho sus encantamientos para que cayga en peligro de la enfermedad y padesca y muera el que quebro el hilo" (1937 [1615]: 275).

Actualmente, tanto en el norte de Argentina como en el sur de Bolivia, persiste la tradición de confeccionar y emplear el hilo zurdo o llok'e, el que participa de una serie de eventos de la vida cotidiana, pero siempre con un sentido mágico y ritual (Rolandi de Perrot y Jiménez de Pupareli 1985). El hilo llok'e aún se confecciona y se utiliza en ocasiones especiales; una de ellas es el $1^{\circ}$ de agosto, en el día de la Pachamama, fecha en que las personas se colocan hilo llok' $e$ en el tobillo, en la muñeca o en el cuello "...porque la tierra está abierta y para no caer dentro de ella..." (Rolandi de Perrot y Jiménez de Pupareli 1985: 280). La concepción general es que el hilo zurdo protege a las personas librándolos de ciertos males. Las autoras documentan el uso del hilo zurdo como elemento con poder mágico para la curación de diferentes enfermedades, tanto en las personas como en el caso de que los enfermos sean animales. Entre los principales "males" o dolencias contra los que el hilo llok'e participa de alguna manera en la curación, se encuentran problemas tan variados como complicaciones durante el parto, dolores corporales, hinchazón de manos, "mal de la tierra", "mal de ojo de agua", "mal de boca", entre otras afecciones (Rolandi de Perrot y Jiménez de Pupareli 1985: 281). Las prácticas

\footnotetext{
17 Según Lira (1944: 589), el término llok'e se define como "izquierda, parte que cae del lado del corazón. Zurdo. Mano izquierda, la siniestra."
} 
sanatorias consisten en hilar hilo llok'e en presencia del enfermo, el que luego se quema y se entierra.

A veces el hilo se corta en trozos sobre la parte afectada o forma parte de infusiones que se dan de beber al paciente. Generalmente se coquea y se hecha alcohol a la tierra mientras se acompaña la actuación del hilo llok'e (Rolandi de Perrot y Jiménez de Pupareli 1985: 280-283). Por lo tanto, podemos observar que en todos los casos existe alguna vinculación entre el hilo llok'e y la tierra, ya sea porque éste se entierra, porque se realiza conjuntamente alguna ceremonia vinculada con una ofrenda a la tierra (chaya), o porque la enfermedad que se trata de curar procede de la Pachamama. Al respecto, Rolandi de Perrot y Jiménez de Pupareli (1985) interpretan que

"El hilado normal es un hecho cultural que transforma la materia prima dada por la naturaleza. El hilado al revés es el opuesto al producto humano y parece tener la propiedad de volver al seno de la tierra, a la naturaleza misma. Su fuerza reside justamente en eso" (1985: 285).

En apoyo de esta hipótesis que señala una estrecha relación entre la madre tierra y el concepto de llok'e, que Müller y Müller documentan que en la comunidad agrícola ganadera de Q'ero (Depto. Cuzco):

"El principio fundamental del orden del cosmos es el dualismo asimétrico, al que llaman "yanantin". Los dos polos del "yanantin" son: el masculino, llamado "phaña" que corresponde al principio patriarcal. El femenino llamado "lloq'e" que corresponde al principio matriarcal" (1984: 164).

Este tipo de hilado también participa con sus propiedades protectoras en ciertos aspectos vinculados con el tejido. Así, por ejemplo, el hilo zurdo suele colocarse en un ovillo para que la lana no se enrosque y a la vez sirva de elemento protector para la tela y, en consecuencia, proteja también a la persona que use la prenda. Igualmente con un sentido de protección, el hilo torsionado a la izquierda puede emplearse como elemento en las primeras pasadas de trama al tejer una tela "...para evitar que venga el diablo" (Rolandi de Perrot y Jiménez de Pupareli 1985: 281). Este poder del hilo llok'e también se manifiesta en el hecho de que ciertos textiles utilizados en algunas ceremonias o fiestas rituales se confeccionan con hilos zurdos. Así, chuspas, inkuñas o llijllas que se utilizan para la ceremonia de la "señalada" pueden presentar ciertas partes tejidas con hilo llok'e, y también los cordeles usados para florear o señalar a los animales se confeccionan en lana hilada llok'e (Rolandi de Perrot y Jiménez de Pupareli 1985: 283).

También Fung (1990, cit. en Agüero 1994: 140) documenta, para algunas regiones de Perú, el carácter simbólico del llok'e, ya que

“...de acuerdo a las creencias muy difundidas, el llok'e está dotado de propiedades mágicas. Protege a las gentes (...) de maleficios, malos espíritus y enfermedades. Es una ofrenda obligada a la Pachamama."

Un dato relevante para este análisis, que se desprende de los relatos de los informantes entrevistados por Rolandi de Perrot y Jiménez de Pupareli (1985) es que, en la mayor parte de los casos, el hilo llok'e es confeccionado con hilos de dos colores o hilado moliné, pero siempre deben ser de tonos contrastantes. La combinación más frecuente es el negro con el blanco (llamado hilo "overo"), aunque también pueden combinarse hilos de colores como por ejemplo rojo y negro, amarillo y morado, etc. Este dato es importante porque permite asociar al hilo que forma el lazo en la parte inferior de la manta con las dos características presentadas por el hilo llok'e: dirección de torsión final izquierda e hilado de tipo moliné.

Un último elemento que nos permite relacionar nuestro hallazgo con este tipo de hilo, es el hecho de que el llok'e también está vinculado con el ámbito funerario, ya que es ese el contexto en el que se recuperó. Rolandi de Perrot y Jiménez de Pupareli (1985: 282) documentan que cuando una persona fallece los parientes le confeccionan una cuerda de color "overo", hilada en llok'e, que atan a la cintura del muerto. También los familiares y vecinos del muerto se atan hilos llok'e en el cuello, muñecas o tobillos “...para que las almas se vayan, para que no se queden junto a ellos y para que no se enfermen" (Rolandi de Perrot y Jiménez de Pupareli 1985: 283). De esta manera el hilo llok'e sigue desempeñando también en este contexto la función principal de protección y rechazo de los peligros, en este caso sobrenaturales. 
Este importante contenido mágico religioso de los hilos con torsión izquierda y de colores contrastantes en la textilería actual de la puna argentina y boliviana, es lo que me lleva a destacar la presencia de un hilo con estas dos características de construcción como elemento superestructural en una de las piezas textiles recuperadas en la tumba. Además, el hecho de que se trate de un elemento agregado a la pieza con posterioridad a su confección permite inferir, con mayores probabilidades, su asociación con algún aspecto vinculado con el ritual funerario.

Escaleras al cielo: Los nudos rituales en prendas funerarias

He mencionado que Rolandi de Perrot y Jiménez de Pupareli (1985) registran que, en la zona de la puna argentina-boliviana, cuando una persona muere, sus parientes le confeccionan una cuerda overa, hilada en llok'e, la que atan a la cintura del fallecido. Las autoras también mencionan que

“...la cruzan adelante colgando dos tiras en las que hacen nudos, tres o cuatro; no pudieron precisar exactamente cuántos son. Esta cuerda recibe el nombre de "milagros". También se usa en forma similar en Chile” (1985: 282).

Un informante relató que, a la muerte de su abuelo

"Le pusieron en la cintura un cordón overo que hicieron en ese momento, hilado llok'e. Vinieron todos los parientes y, mientras bebían, el hermano del abuelo y los primos confeccionaron la soga llok'e con tres nudos" (1985: 282).

Las autoras mencionan que en la vertiente transandina también se registra el uso de esta cuerda que es atada a la cintura del muerto y a la que se le efectúan una serie de nudos, con el fin de desempeñar alguna función en el rito funerario, aunque no mencionan si los entrevistados en el sector argentino hacen alguna referencia a cuál podría ser el papel desempeñado por estos nudos en la cuerda o "milagros" (Rolandi de Perrot y Jiménez de Pupareli 1985).

Por su parte, Hoces de la Guardia y Rojas (2000), realizaron un relevamiento de las artesanías textiles actuales en el sector del Loa y el Salar de Atacama, registrando la presencia de un elemento textil llamado "signo" o "símbolo", que creo re- presentaría la prenda equivalente al "milagros" del sector puneño argentino. Esta interpretación se desprende de la descripción que, a partir de los datos de los informantes, presentan las autoras. El "signo" o "símbolo"

“...es una prenda de uso ritual que se le pone en la cintura al difunto. Consiste en un cordón de aproximadamente $2 \mathrm{~m}$ de largo realizado con mismeado. Posee nudos (número que varía según el entrevistado) los que tienen por objetivo ayudar al muerto a llegar al cielo" (Hoces de la Guardia y Rojas (2000).

Y aquí tenemos una referencia acerca de la función cumplida por estos nudos, los que son confeccionados por los parientes con el fin de ayudar al muerto a sortear algunas de las dificultades con las que se enfrenta en su tránsito hacia el lugar de descanso final. Al referirse a una de las entrevistadas, Hoces de la Guardia y Rojas mencionan:

"Evangelista dice que son siete los nudos del ritual funerario, el signo o símbolo que los hombres misman. Siete podría representar siete cielos, los nudos son para subir al cielo" (2001).

Considero que estos datos son importantes, al menos, para proporcionar un marco de referencia en el que puede ser factible interpretar una característica identificada en uno de los bordes de un textil procedente de la tumba de PP9. Se trata de una posible bolsa funeraria, la que presentaba los dos cordones laterales de una honda anudados en la porción central de la pieza. Al efectuar el análisis de sus bordes pude identificar un detalle bastante atípico. Un conjunto de elementos de urdimbre -seis hilos- presentan una longitud mayor que la que poseen los sectores de borde conservados. Estos seis elementos están anudados por un séptimo hilo de urdimbre y, a continuación, todo este conjunto de hilos presenta una sucesión de diez medios nudos (half knot) separados por distancias variables entre 1 y $2 \mathrm{~cm}$. Este atributo de la prenda no tiene, aparentemente, vinculación con ninguna función práctica, ni tampoco parece representar un elemento decorativo, por su escasa visibilidad en el tejido. Descartadas las posibilidades de una relación con funciones exclusivamente tecnológicas o meramente decorativas, pensé en la posibilidad de que estos nudos en la prenda tuvieran alguna relación en el marco de los significados simbólicos de tipo rituales o que se trata- 
ra de atributos con algún poder "mágico" asociado al evento de la muerte. No intento de esta manera hacer una transposición mecánica entre los nudos rituales confeccionados en prendas como el "signo" o "símbolo" en Chile, o la cuerda de "milagros" en el sector argentino, con los nudos identificados en la prenda de PP9; pero creo que esta es una hipótesis interesante de considerar, teniendo en cuenta que se ha documentado la existencia actual de este tipo de práctica y del significado a ella asociado. Tratándose de una prenda recuperada en un contexto funerario y no existiendo otras interpretaciones alternativas para explicar la presencia de los nudos en la tela, -función práctica o decorativa- la función ritual de estos nudos y su asociación con alguna creencia vinculada con la nueva etapa por la que atraviesa el difunto, es una respuesta que no debe ser descartada. Enmarcada en las mismas consideraciones, también quisiera recordar aquí las características presentadas por uno de los elementos de cordelería asociados al ajuar. Me refiero a la larga cuerda de casi $5 \mathrm{~m}$ de largo y $11 \mathrm{~mm}$ de espesor que presentaba una serie de nudos en diferentes tramos de su extensión. La cuerda ritual "signo", "símbolo" o "milagros" es una cuerda que se ata a la cintura del muerto y a la que se le efectúan una serie de nudos por lo que, en tanto dispongamos de datos adicionales procedentes de otros contextos similares, tampoco puedo descartar del todo la posibilidad de una asociación entre este tipo de artefactos y la larga cuerda recuperada en el contexto funerario de PP9. El hecho de que la tumba haya sido reabierta plantea la posibilidad de que, al quitar el cuerpo, la soga fuera retirada de una posición en relación directa con el difunto y dispuesta en forma enrollada en el sitio donde fue recuperada durante nuestra intervención arqueológica.

\section{Consideraciones finales. Las tres dimensiones de análisis en juego}

Las tres dimensiones de aproximación a la materialidad textil que he planteado en este trabajo han brindado resultados relevantes para acercarnos al conocimiento de diferentes aspectos de los grupos que produjeron y emplearon estas prendas.

Desde la dimensión tecnológica, además de caracterizar particularmente a la muestra recuperada en PP9, he podido trazar relaciones con atri- butos tecnológicos y de construcción exhibidos por textiles tempranos, recuperados tanto en el actual territorio argentino como en la vertiente trasandina. Considero que gran parte de la relevancia que plantea este análisis se vincula con la extremadamente fragmentaria información que poseemos, en la región Noroeste de Argentina, respecto de materiales textiles con una cronología comprendida entre el 2000 y el 1000 AP.

Algunos de los principales rasgos tecnológicos presentados por la muestra procedente de Antofagasta de la Sierra son los que menciono a continuación. Un predominio de la estructura de tejido llano en faz de urdimbre, registrándose un único caso de una prenda construida en faz de trama y decorada con la técnica de tapicería entrelazada, así como un claro dominio de la dirección final de torsión derecha en los hilados. Una clara selección de los hilados utilizados en la estructura de las prendas de acuerdo con diferentes criterios entre los que destaco el de visibilidad, con hilados monocromos en los elementos visibles y molinés en los que permanecen ocultos al observador; el de funcionalidad, que muestra el empleo de gruesos hilados mismido y jaspe para la construcción de la manta y la túnica, ambas prendas de gran abrigo y, desde lo que puede considerarse como un criterio de eficacia tecnológica, destaco que los hilos de la urdimbre se diferencian de los de trama, en cada tejido, por su menor diámetro y más elevado grado de torsión, lo que les otorga una mayor resistencia a las tensiones y roces sufridos durante el proceso de manufactura. Las prendas exhiben una importante variedad de técnicas decorativas estructurales, así como el empleo de elementos superestructurales -costuras, bordados y elementos agregadospara lograr diferentes efectos decorativos. Entre las primeras, destacamos el registro más temprano documentado hasta el momento, para el sector correspondiente al territorio argentino, de la técnica de urdimbres transpuestas y/o divergentes. Este constituye un rasgo técnico característico del área andina meridional, y presenta en el textil recuperado en PP9 rasgos de construcción particulares sobre los que no he encontrado registros de otros casos comparables.

Los rasgos en común con ejemplares tempranos procedentes de la vertiente trasandina corresponden tanto a atributos formales como tecnológicos. 
En el primer caso, se ha podido documentar la presencia de algunos de los elementos más frecuentes de la vestimenta funeraria andina, con la identificación de una manta, una chuspa, un unku, una posible faja y probables bolsas funerarias. En segundo lugar, resulta de interés sintetizar los atributos técnicos o rasgos textiles compartidos, entre las piezas de PP9 y textiles de sitios del norte de Chile que presentan una cronología similar. ${ }^{18}$ Destaco el empleo, para la confección de túnicas y mantas, de la técnica de faz de urdimbre, generalmente con decoración listada, la utilización de tramas múltiples y de hilados muy gruesos que dan un aspecto mullido y una textura gruesa a las prendas. También se ha registrado la presencia de una costura decorativa en forma de cadeneta en el borde en tres prendas de PP9, rasgo que es común entre las mantas y túnicas del Formativo chileno. Por último, el empleo de la técnica de peinecillos también constituye un rasgo decorativo temprano compartido por las piezas de ambas vertientes andinas. Por otra parte, entre las diferencias más notables se puede destacar que, mientras que la técnica de enlazado o malla fue la más utilizada para la confección de pequeñas bolsas en el norte chileno, la chuspa de PP9 ha sido elaborada en telar, con empleo de urdimbres torsionadas para la conformación de un complejo diseño decorativo.

Desde lo que he denominado la dimensión iconográfica ha sido posible analizar algunos de los principios estéticos y pautas de simetría que gobiernan la construcción de los diseños decorativos en las prendas. Se ha sugerido que algunos de estos diseños, como el de listas verticales contrastantes, podrían remitir a marcos de significado más amplios (Cereceda 1990) y, aunque para los textiles arqueológicos no podamos contar con información que nos permita develar los significados profundos de la decoración, tampoco podemos dejar de notar la presencia de ciertos diseños decorativos que se han mantenido casi inalterables en el tiempo, desde las prendas arqueológicas hasta la textilería tradicional actual. Tal es el caso de los listados verticales, así como la organización de los colores y las figuras en este y otros diseños presentes en las telas, respondiendo siempre la decoración a principios de simetría

\footnotetext{
18 Correspondientes a las fases tardías del Formativo (500 AC - 500 DC) según Agüero y Cases (2000).
}

axial, con imagen de tipo especular y bilateral. Con respecto al uso del color, en todos los casos se han empleado los colores naturales de las fibras, pero usando los tonos en oposición, aprovechando un efecto de contraste al combinarlos para la creación de los diseños.

Los diseños decorativos presentes en algunas de las piezas me permitieron, además, emprender un análisis comparativo con los diseños presentes en otros soportes, tales como la cerámica y el arte rupestre. Esto ha posibilitado contextualizar a las telas a través de un estudio estilístico comparativo más amplio que ha arrojado resultados coherentes con la información desprendida del fechado radiocarbónico. Las relaciones de semejanza estilística identificadas entre la chuspa de PP9 y representaciones plasmadas en el arte rupestre de Antofagasta de la Sierra y en piezas cerámicas procedentes del área valliserrana (Valle de Abaucán y Hualfín), vinculan a esta prenda con el denominado estilo Ciénaga del N.O.A. A su vez, esta pequeña bolsa presenta un conjunto de semejanzas técnico estructurales y estilísticas con un ejemplar recuperado de un fardo funerario de San Pedro de Atacama. Las relaciones tecnológicas identificadas entre los dos textiles permitieron proponer un origen o tradición textil en común para ambos ejemplares. Este lugar de origen, de acuerdo con las características técnicas de elaboración más frecuentes de las bolsas en el norte chileno y los vínculos estilísticos detectados entre la decoración de ambas bolsas y de éstas a su vez con representaciones de piezas cerámicas del área valliserrana catamarqueña, se ubicaría en la región del N.O.A. Este vínculo que propongo entre las dos piezas textiles permite ampliar la información que poseemos sobre el complejo proceso de intercambio de información, bienes y personas que existió entre ambas vertientes de la cordillera andina meridional. A su vez, el contexto funerario de PP9 también ha permitido recuperar elementos foráneos, ${ }^{19}$ los que representan indicadores de intercambio a gran distancia entre los habitantes de la puna y

\footnotetext{
19 Entre los recursos vegetales foráneos recuperados en forma de artefactos o ecofactos se encuentran los siguientes: algarrobo (Prosopis sp.), chañar (Geoffroea decorticans), calabaza (Lagenaria siceraria), sauce criollo (Salix humboldtiana), fibra de palmera (Acrocomia sp.) y porotos (Phaseolus sp.). También se recuperó una valva completa de un caracol marino (Familia Fissurellidae), cuyo origen sea probablemente la vertiente del Pacífico.
} 
los de la región de valles mesotérmicos y cálidos, las selvas occidentales y la vertiente del Pacífico.

La interacción entre los oasis del Salar de Atacama y las poblaciones del N.O.A. ya ha sido planteada y tratada en profundidad por varios autores (Núñez y Dillehay 1995, Tarragó 1989, Llagostera 1995, entre otros) por lo que no me referiré aquí a los principales postulados de estos modelos de interacción y circulación de bienes y personas en la región surandina. Simplemente quiero mencionar que adhiero a la propuesta de Haber (2001), respecto de que las interacciones interregionales en los Andes meridionales durante el primer milenio de la era habrían involucrado

“...bienes de alto valor agregado, escaso volumen y demanda no demográficamente regulada, es decir, no eran bienes de consumo masivo" (2001: 251).

Esto quiere decir, que estas interacciones comprendían, entre otros elementos, bienes de importancia ritual, ceremonial o prestigio, cuya principal finalidad apuntaba "más a la construcción de redes sociales que a la subsistencia humana" (Haber 2001: 252). La bolsita textil procedente del N.O.A., recuperada en el contexto funerario de San Pedro de Atacama, representa perfectamente el tipo de bienes y de conocimiento tecnológico que se ponía en movimiento con estos circuitos de intercambio: bienes de alto valor simbólico o ritual y portadores de una tecnología que era desconocida o apenas conocida por el grupo o individuos receptores del bien. El contexto de recuperación de la pieza - una tumba- agrega más elementos para apoyar el fuerte carácter simbólico de estos bienes en circulación, así como también las particulares características técnicas de elaboración y los patrones de decoración de la pieza textil, hacen de esta prenda un ejemplar verdaderamente notable entre los materiales procedentes de los contextos atacameños.

Finalmente, me he aproximado a las prendas textiles desde lo que he denominado la dimensión ritual o mágico religiosa. Esto ha sido posible, en primer lugar, por las características particulares del contexto de recuperación de las telas, las que formaban parte de un ajuar funerario. En segundo lugar, la persistencia en algunas regiones de los Andes meridionales de ciertas prácticas y creencias vinculadas con el poder mágico del hilo llok'e o zurdo, y la identificación en la muestra de un hilo con estas características de elaboración, ha brindado la posibilidad de abordar esta dimensión sobrenatural de los hilados. El hilado con torsión izquierda participa en numerosas curaciones y ceremonias vinculadas con el culto a la Pachamama, así como con algunos aspectos relacionados con la muerte y el ritual funerario. También se ha documentado, tanto en zonas de la puna argentina y en los salares del norte de Chile, el simbolismo asociado a cuerdas con nudos rituales, los que tienen la función de ayudar al alma del difunto a realizar el ascenso hacia el cielo (Rolandi de Perrot y Jiménez de Pupareli 1985, Hoces de la Guardia y Rojas 2000). Tanto el borde de una de las telas como una extensa cuerda recuperadas en la tumba de PP9 presentan un conjunto de nudos y otras características particulares que podrían asociarse con este tipo de funciones rituales de ciertas prendas funerarias.

Como he planteado antes de abordar estas tres dimensiones de análisis, considero que estas son sólo algunas de las metodologías posibles que pueden ser empleadas para introducirse en el conocimiento de una tecnología tan compleja y que enlazó aspectos tan diferentes de la vida y la muerte de las poblaciones andinas, como lo es el universo de los textiles arqueológicos.

Agradecimientos Quisiera agradecer a todas las personas que, de diferentes formas, estuvieron relacionadas con mi acceso al mundo de los textiles. En primer lugar, y muy especialmente, a Diana Rolandi de Perrot, por toda la paciencia y la energía puesta en brindarme sus conocimientos y su experiencia en el análisis de los textiles durante mi pasantía en el INAPL. Sin su apoyo este trabajo no habría sido posible. A mi querida amiga Carole Sinclaire, además de los buenos momentos compartidos en Turi y San Pedro, por invitarme a participar de las reuniones del Comité Nacional de Conservación Textil y, de esa manera, recibir el apoyo y el consejo de algunos de sus integrantes. Entre ellos quisiera destacar mi especial agradecimiento a Susana Renard, por el entusiasmo con que siempre atendió mis dudas y por el gran estímulo que representaron para mí sus opiniones. A Carolina Agüero, por ser tan buena anfitriona en San Pedro, por permitirme el acceso a la colección textil del Museo Arqueológico R. P. G. Le Paige y la consulta a los informes 
inéditos de los Proyectos FONDECYT que ella dirige. A Ana María Rojas y Soledad Hoces de la Guardia por permitirme conocer el informe inédito sobre su investigación de las artesanías textiles en la región del Loa. A Mary Frame por su interés y sugerencias. A Carlos Aschero, por la lectura del presente trabajo y sus valiosos aportes, por su estímulo constante.

\section{REFERENCIAS CITADAS}

AGÜERO, C., 1994. Madejas, hilados y pelos: Los turbantes del Formativo Temprano en Arica, Norte de Chile. Tesis para obtener el título de Arqueóloga. Departamento de Antropología, Facultad de Ciencias Sociales, Universidad de Chile, Santiago.

- 1995. El Cementerio "Protonazca" de Pisagua (D). Estudio de la textilería. Actas del XIII Congreso Nacional de Arqueología Chilena. Hombre y Desierto 9 (II): 7-16, Antofagasta 1994.

2000. Tarapacá - 40 y la textilería formativa del norte de Chile. Actas de la XIII Reunión Anual del Comité Nacional de Conservación Textil, pp. 7-18, Arica 1999.

AGÜERO, C. y B. CASES, 2000. Quillagua y los textiles formativos del Norte Grande de Chile. Actas del XV Congreso Nacional de Arqueología Chilena, Arica. En prensa.

ASCHERO, C., 1988. Pinturas rupestres, actividades y recursos naturales. Un encuadre arqueológico. Arqueología Contemporánea Argentina, pp. 109-145. Ediciones Búsqueda, Buenos Aires.

BRUGNOLI, P. y S. HOCES DE LA GUARDIA, 1998. En la búsqueda del sentido de las estructuras y técnicas textiles: El torzal. Boletín del Comité Nacional de Conservación Textil 3: 71-79, Santiago.

CASES, B., 2000. Textiles formativos de la cuenca del Loa y de Atacama. Actas de la XIII Reunión Anual del Comité Nacional de Conservación Textil, pp. 35-44, Arica 1999.

CERECEDA, V., 1990. A partir de los colores de un pájaro... Boletín del Museo Chileno de Arte Precolombino 4: 57-104, Santiago.

CONKLIN, W. y B. CONKLIN, 1996/97. Un textil Aguada en contexto atacameño. Cuadernos del INAPL 17: 187-203, Buenos Aires.

D'HARCOURT, R., 1977. Textile of the ancient Perú and their techniques. Washington D.C.

EMERY, I., 1966. The primary structure of fabrics. The Textile Museum. University of Washington Press, Washington D.C.

GALLARDO, F., 1993. La sustancia privilegiada: Turbantes, poder y simbolismo en el Formativo del norte de Chile. En Identidad y prestigio en los Andes. Catálogo de exposición, pp. 11-25, Museo Chileno de Arte Precolombino, Santiago.
GISBERT, T., S. ARCE y M. CAJIAS, 1987. Arte textil y mundo andino. Ed. Gisbert y Cía. S.A, La Paz.

GONZALEZ, A. R., 1983. Nota sobre religión y culto en el Noroeste argentino prehispánico. A propósito de unas figuras antropomorfas del Museo de Berlín. BaesslerArchiv, Neue Folge, Band XXXI, pp. 219-282. Verlag Von Dietrich Reimer - Berlín.

GONZALEZ, A. R. y J. PEREZ, 2000. Argentina indígena. Vísperas de la conquista. Colección Historia Argentina I. Editorial Paidós, Buenos Aires.

GORDILLO, I., M. BALDINI y M. F. KUSCH, 2000. Entre objetos, rocas y cuevas: Significado y relaciones entre la iconografía rupestre y mobiliar de Aguada. En Arte en las rocas. Arte rupestre, menhires y piedras de colores en Argentina, M. M. Podestá y M. de Hoyos (Eds.), pp. 101-112. S.A.A. y A.I.N.A, Buenos Aires.

HABER, A., 2001. El oasis en la articulación del espacio circumpuneño. Actas del XIII Congreso Nacional de Arqueología Argentina T I: 251-268, Córdoba.

HOCES DE LA GUARDIA, S. y A. M. ROJAS, 2001. Proyecto Textiles atacameños: Investigación, registro y diagnóstico de las artesanías textiles del Loa y el Salar de Atacama. Ponencia presentada en la XV Reunión Anual del Comité Nacional de Conservación Textil, San Pedro de Atacama.

HORTA, H., 2000 Ms. Iconografía del Período Formativo (Norte Grande de Chile). Informe de Avance Proyecto FONDECYT 1990168.

LIRA, J., 1944. Diccionario Kechuwa - Español. Departamento de Investigaciones Regionales. Instituto de Historia, Lingüística y Folcklore XII. Universidad Nacional de Tucumán, Tucumán.

LOPEZ CAMPENY, S. M. L., 2001a. Actividades domésticas y organización del espacio intrasitio. El sitio Punta de la Peña 9. Antofagasta de la Sierra (Prov. de Catamarca). Tesis de Grado de Arqueología. Facultad de Ciencias Naturales e I.M.L., Universidad Nacional de Tucumán, Tucumán.

— 2001b. El hogar, los ancestros y el corral: Reocupación y variabilidad en el uso del espacio en unidades domésticas arqueológicas (Sitio Punta de la Peña 9, Antofagasta de la Sierra, Catamarca). Actas del XIV Congreso Nacional de Arqueología Argentina, Universidad Nacional de Rosario, Rosario. En prensa. 
- 2001c. La trama del desierto. Textiles tempranos de Antofagasta de la Sierra (Puna Meridional Argentina). Actas de la XV Reunión Anual del Comité Nacional de Conservación Textil, San Pedro de Atacama. En prensa.

LLAGOSTERA, A., 1995. El componente cultural Aguada en San Pedro de Atacama. Boletín del Museo Chileno de Arte Precolombino 6: 9-34, Santiago.

MACKO, S., J. ARANIBAR, M. G. COLANERI, S. M. L. LOPEZ CAMPENY y C. A. ASCHERO, 2001. Punta de la Peña 9: Análisis de isótopos estables de un sitio agropastoril de la Puna Meridional Argentina (Antofagasta de la Sierra, Catamarca). Actas del XIV Congreso Nacional de Arqueología Argentina, Universidad Nacional de Rosario, Rosario. En prensa.

MARTEL, A., 2000. Estudio arqueológico del arte rupestre del sitio Cacao 3 (Cc3), Dto. Antofagasta de la Sierra, Prov. de Catamarca. Tesis de Grado de Arqueología. Facultad de Ciencias Naturales e I.M.L., Universidad Nacional de Tucumán, Tucumán.

MOSTNY, G., 1952. Una tumba de Chiu Chiu. Boletín del Museo de Historia Natural XXVI: 1-55, Santiago.

MÜLLER, T. y E. MÜLLER, 1984. Cosmovisión y celebraciones del mundo andino. Allpanchis 3, Año XIV, vol. XX, pp. 161-176, Cuzco.

NUÑEZ, L. y T. DILLEHAY, 1995. Movilidad giratoria, armonía social y desarrollo en los Andes Meridionales: Patrones de tráfico e interacción económica. $2^{\mathrm{a}}$ Edición. Universidad Católica del Norte, Antofagasta.

OLIVERA, D., 1992. Tecnología y estrategias de adaptación en el Formativo (Agroalfarero Temprano) de la Puna Meridional Argentina. Un caso de estudio: Antofagasta de la Sierra (Pcia. de Catamarca, R.A.). Tesis de Doctorado. Universidad Nacional de la Plata, La Plata.

OLIVERA, D. y M. PODESTA, 1993. Los recursos del arte: Arte rupestre y sistemas de asentamiento-subsistencia formativos en la Puna Meridional Argentina. Arqueología 3: 93-126, Buenos Aires.

PODESTA, M., 1989. Punta del Pueblo: Expresiones del arte rupestre agroalfarero en la Puna Argentina. Boletín SIARB 3: 38-47, La Paz.

PODESTA, M. y L. MANZI, 1995. Arte rupestre e interacción interregional en la Puna Argentina. Cuadernos del Instituto Nacional de Antropología y Pensamiento Latinoamericano 16: 367- 399, Buenos Aires.

PODESTA, M., L. MANZI, A. HORSEY y M. FALCHI, 1991. Función e interacción a través del análisis temático en el arte rupestre. En El arte rupestre en la arqueología contemporánea, M. Podestá, M. I. Hernández Llosas y S. Renard de Coquet (Eds.), pp. 40-53, Buenos Aires.
POMA DE AYALA, F. G., 1937 [1615]. Nueva crónica y buen gobierno. Instituto de Etnología de París. Edición facsimilar.

RENARD, S., 1997. Objetos textiles, pasos y caminantes trasandinos. Piezas similares y rasgos comunes en textiles arqueológicos de Argentina y Chile. Estudios Atacameños 14: 291-305, San Pedro de Atacama.

- 1999. Textiles arqueológicos en el Noroeste de la Argentina. 100 siglos de actividad textil. En Masked histories: A re-examination of the Schreiter collection from Northwestern Argentina, P. Stemborg and A. Muñoz (Eds.). Etnologiska Studier (43): 67-95, Goteborg.

ROLANDI DE PERROT, D., 1973. Los textiles tastileños. En Tastil. Una ciudad preincaica argentina, E. Cigliano (Proyecto y dirección), Cap. VI, pp. 231-399. Ediciones Cabargón, Buenos Aires.

- 1979. Los tejidos de Río Doncellas, Dpto. Cochinoca, Jujuy. Jornadas de Arqueología del N.O.A. Antiquitas. F.F. y L. Universidad del Salvador, Buenos Aires.

ROLANDI DE PERROT, D. y D. JIMENEZ DE PUPARELI, 1985. La tejeduría tradicional de la Puna Argentino Boliviana. Cuadernos del I.N.A. 10: 205-289, Buenos Aires.

ROLANDI DE PERROT, D y R. NARDI, 1978. 1000 años de tejido en la Argentina. Instituto Nacional de Antropología, Buenos Aires.

ROWE, A., 1977. Warp patterned weaves of the Andes. The Textile Museum, Washington D. C.

SINCLAIRE, C. 1995. La tradición de fajas y cintas trenzadas en el Período Medio e Intermedio Tardío del Valle de Azapa: Una proposición tipológica. Actas del XIII Congreso Nacional de Arqueología Chilena. Hombre y Desierto 9 (II): 55-67, Antofagasta 1994.

- 1997. Pinturas rupestres y textiles formativos en la región atacameña: Paralelos iconográficos. Estudios Atacameños 14: 327-338, San Pedro de Atacama.

- 2001. Tapicerías polícromas del Período Formativo en la región atacameña, norte de Chile: Un caso de estudio. Actas de la XV Reunión Anual del Comité Nacional de Conservación Textil, San Pedro de Atacama. En prensa.

TARRAGO, M., 1989. Contribución al conocimiento arqueológico de las poblaciones de los oasis de San Pedro de Atacama en relación con los otros pueblos puneños, en especial, el sector septentrional del Valle Calchaquí. Tesis para optar al título de Doctor en Historia, Facultad de Humanidades y Artes, Universidad Nacional de Rosario, Rosario.

ULLOA, L., 1974. Análisis del material textil del sitio "El Laucho" PLM-7. Revista Chungara 3: 75-105, Arica. 